NBER WORKING PAPER SERIES

\title{
ACCOUNTING FOR U.S. REAL EXCHANGE RATE CHANGES
}

\author{
Charles Engel
}

Working Paper 5394

\section{NATIONAL BUREAU OF ECONOMIC RESEARCH 1050 Massachusetts Avenue \\ Cambridge, MA 02138 \\ December 1995}

I thank participants at seminars at the Federal Reserve Bank of Kansas City, the University of Washington and the Castor Workshop for useful comments. I thank Mike Hendrickson for outstanding research assistance. Part of the work for this project was completed while I was a visiting scholar at the Federal Reserve Bank of Kansas City. The National Science Foundation provided support for this project under grant number SBR-932078. This paper is part of NBER's research program in International Finance and Macroeconomics. Any opinions expressed are those of the author and not those of the National Bureau of Economic Research.

(C) 1995 by Charles Engel. All rights reserved. Short sections of text, not to exceed two paragraphs, may be quoted without explicit permission provided that full credit, including $\odot$ notice, is given to the source. 
NBER Working Paper 5394

December 1995

\title{
ACCOUNTING FOR U.S. REAL EXCHANGE RATE CHANGES
}

\begin{abstract}
This study measures the proportion of U.S. real exchange rate movements that can be accounted for by movements in the relative prices of non-traded goods. The decomposition is done at all possible horizons that the data allow -- from one month up to thirty years. The accounting is performed with five different measures of non-traded goods prices and real exchange rates, for exchange rates of the U.S. relative to a number of other high income countries in each case. The outcome is surprising -- relative prices of non-traded goods appear to account for essentially none of the movement of U.S. real exchange rates at any horizon. Only for one crude measure, which uses the aggregate producer price index as an index of traded goods prices, do non-traded goods prices seem to account for more than a tiny portion of real exchange rate changes. This pattern appears to be true even during fixed nominal exchange rate episodes. Special attention is paid to the U.S. real exchange rate with Japan. The possibility of mismeasurement of traded goods prices is explored.
\end{abstract}

\section{Charles Engel}

Department of Economics University of Washington

Box 353330

Seattle, WA 98195-3330

and NBER 
The real exchange rate is a measure of one country's overall price level relative to another country's. It is often associated with the price of non-traded goods relative to traded goods. To see why, consider a price index for a country that is a geometric weighted average of traded and non-traded goods prices:

$$
p_{t}=(1-\alpha) p_{t}^{T}+\alpha p_{t}^{N}
$$

where $p_{t}$ is the $\log$ of the price index, $p_{t}^{T}$ is the $\log$ of the traded goods price index, $p_{t}^{N}$ is the $\log$ of non-traded goods price index, and $\alpha$ is the share that non-traded goods take in the price index. Letting a $*$ represent the foreign country, we can also write

$$
\mathrm{p}_{\mathrm{t}}^{*}=(1-\beta) \mathrm{p}_{\mathrm{t}}^{\mathrm{T}^{*}}+\beta \mathrm{p}_{\mathrm{t}}^{\mathrm{N}^{*}}
$$

where $\beta$ is non-traded goods' share in the foreign price index. Then the real exchange rate is given by:

$$
\mathrm{q}_{\mathrm{t}}=\mathrm{x}_{\mathrm{t}}+\mathrm{y}_{\mathrm{t}}
$$

where

$$
\begin{aligned}
& \mathrm{q}_{\mathrm{t}} \equiv \mathrm{s}_{\mathrm{t}}+\mathrm{p}_{\mathrm{t}}^{*}-\mathrm{p}_{\mathrm{t}} \text {, }
\end{aligned}
$$



$$
\begin{aligned}
& y_{t} \equiv \beta\left(p_{t}^{N^{*}-} p_{t}^{\left.T^{*}\right)}-\alpha\left(p_{t}^{N}-p_{t}^{T}\right)\right. \text {. }
\end{aligned}
$$

Here, $s_{1}$ is the log of the domestic currency price of foreign currency.

Equation (1) indicates that the log of the real exchange rate is composed of two parts: the log of the relative price of traded goods between the countries, $x_{t}$; and, a component that is a weighted difference of the log of the relative price of non-traded to traded goods prices in each country, $y_{1}$.

The real exchange rate for the U.S. relative to other high income countries has fluctuated dramatically over the past 25 years. The short-term and longer-term movements have been much greater than what the U.S. witnessed over the 25 -year period immediately 
preceding that. Most of the recent theoretical literature on real exchange rates has emphasized movements in the non-traded goods component, $y_{t} \cdot{ }^{1}$ This study is an attempt to measure how significant the non-traded goods component is in U.S. real exchange rate movements.

Determining precise price indexes for non-traded goods and traded goods is an impossible task given the quality of data available. Still, since movements in the relative price of non-traded goods play such a large role in real exchange rate theory, it seems a worthwhile task to attempt some measure of this price. In this paper, we look at five measures of non-traded goods prices. The first is based on consumer price indexes, and classifies services and housing as non-tradable, and commodities as tradable. The second is constructed from an OECD database of output prices that previous studies have used to produce traded and non-traded goods price indexes. ${ }^{2}$ The third uses price deflators for personal consumption expenditures, letting the price index for expenditure on goods be the measure of traded goods prices and the price index for services be the measure of non-traded goods prices. ${ }^{3}$ The fourth measure is a cruder one: the aggregate producer price index is used as the measure of traded goods prices, and the non-traded component, $y_{t}$, is constructed from aggregate CPIs relative to aggregate PPIs. Finally, it has been argued that a large component of consumer prices consists of nontraded marketing services. ${ }^{4}$ Data is available from Japan on prices for thirty-six of the services involved in turning products from commodities to finished consumer products. The behavior of these prices relative to the general price level is investigated.

\footnotetext{
Recent examples include Asea and Mendoza (1994), Brock (1994), Brock and Turnovsky (1994), De Gregorio, Giovannini and Krueger (1994), Samuelson (1994), De Gregorio and Wolf (1994), Razin (1995) and Obstfeld and Rogoff (1995).

2 See De Gregorio, Giovannini and Wolf (1994) and De Gregorio and Wolf (1994)

3 This measure has been used by Kakkar and Ogaki (1994) and Stockman and Tesar (1995)

4 This argument is expounded in Engel (1993), Froot and Rogoff (1994) and Engel and Rogers (1994).
} 
Actually, this is not the first study to construct traded and non-traded goods price indexes. 5 However, there are two serious problems with earlier work. All of the previous studies look only at the price of non-traded to traded goods for an individual country. But, the non-traded goods component, $y_{t}$, is a relative relative price -- the relative price of non-tradables to tradables in one country relative to that relative price in another country. So, simply looking at $\mathrm{p}_{1}^{\mathrm{N}}-\mathrm{p}_{1}^{\mathrm{T}}$ will not reveal much about $\mathrm{q}_{1}$. We must look at how $\alpha\left(p_{1}^{N}-p_{1}^{T}\right)$ moves relative to $\beta\left(p_{1}^{N^{*}}-p_{1}^{T^{*}}\right)$. The second problem is that these studies do not look at how important the non-traded prices component is in the overall movement of the real exchange rate. That is, they do not compare contribution of movements in $y_{t}$ in the overall change in the real exchange rate to the contribution of movements in $x_{1} \cdot{ }^{6}$

Some theories of real exchange rate movements distinguish short-run from long-run behavior. For example, if nominal prices are sticky and nominal exchange rates fluctuate greatly, then short-run movements of the real exchange rate can be dominated by movements in the tradable component, $x_{t}$. As prices adjust over time, the relative prices of the non-traded goods component, $y_{t}$, becomes more important. ${ }^{7}$ In examining the relative size of the $x_{t}$ and $y_{t}$ components, it is therefore necessary to look at different horizons. This study looks at the average change and the variance of the change in these components at all horizons that the data allow -- in some cases from horizons as short as one month to as long as thirty years.

The numbers presented here should be thought of as accounting numbers, not as statistics. The numbers do not represent sample measures of some underlying population

\footnotetext{
5 For example, see De Gregorio, Giovannini and Wolf (1994), De Gregorio and Wolf (1994), Kakkar and Ogaki (1994) and Stockman and Tesar (1995).

6 Rogers and Jenkins (1995) do decompose the variance of the real exchange rate at four horizons into a component attributable to food prices, and a component attributable to all other goods. literature.

7 See Froot and Rogoff (1994) and Rogoff (1995) for recent surveys of this
} 
parameters. As an analogy, sometimes one might calculate the average height of the persons in a room to get some sort of estimate -- perhaps an estimate of the average height of human beings. That would be a statistic. Other times, one would calculate the average height just because one is interested in knowing how tall the people in the room are on average. The calculations in this paper are more like the latter example. We want to know historically (over the past 20 or 30 years) how much of movements of $q_{k}$ for the U.S. can be attributed to movements in $y_{1}$ ?

The overwhelming impression from the evidence presented here is that the non-traded component has accounted for almost none of the movements in the real exchange rate for the U.S. relative to high-income countries at any horizon. As an empirical matter, knowledge of the behavior of the relative price of non-traded goods contributes virtually nothing to our understanding of the U.S. real exchange rate.

Each of the next four sections looks at the decomposition of the real exchange rate for different measures of traded and non-traded goods prices. Section 5 focuses on the U.S.-Japanese real exchange rate. It describes in more detail why $y_{1}$ accounts for so little of the movement in $\mathrm{q}_{\mathrm{l}}$. Some significant bias can be introduced into our decompositions if there is a particular type of systematic error in the measurement of traded goods prices. Specifically, if the traded goods prices actually contain a significant non-traded component, we may understate the movement in the relative price of non-traded to traded goods. This issue is addressed in section 6. Section 7 summarizes the implications of this study.

\section{Consumer Prices}

This section measures real exchange rates using consumer prices. Monthly OECD data from January 1962 to March 1995 on four seasonally unadjusted price series -- food, all 
goods less food, shelter, all services less shelter -- are available from Datastream for Canada, France, Germany, Italy, Japan and the U.S. A traded goods price index for each country is constructed from the food and all goods less food indexes, and a non-traded goods price index is built from the shelter and all services less shelter indexes. ${ }^{8}$ In general, price indexes average prices over the period they cover. So, in all calculations, the nominal exchange rates are monthly averages from the International Financial Statistics database of the IMF, also available on Datastream.

Clearly these are imperfect measures of traded and non-traded goods. First, it is dubious that some of the items in the traded goods category are actually traded -- for example, restaurant meals. In general, consumer prices probably should be thought of as the price of a joint product: the good itself, and the service that brings the good to market so the consumer can buy it. While the good might be tradable, the marketing service is probably closer to being non-tradable. Conversely, some of the items contained in our non-traded category are probably tradable. Many services, such as financial services, are now traded. The shelter category includes not only rent on dwellings, which is probably legitimately non-traded, but also, for example, the costs of heating the dwelling, which has a large tradable component.

The amount of movement of the exchange rate over a particular period could have two meanings -- the amount of drift or the variance. The mean-squared error -- which is the sum of the squared drift and the variance -- is a comprehensive measure of movement. For each measure, we want to know what portion of the movement of $q_{t}$ can be attributed to $x_{t}$.

There are different ways of decomposing the mean-squared error (and drift and variance) of $q_{t}$ into its $x_{t}$ and $y_{t}$ components, depending on how co-movements of $x_{t}$ and $y_{t}$ are handled. In practice, for all of our measures of $x_{t}$ and $y_{t}$ except the ones described in Section 4, the two series are nearly uncorrelated (in first-differences) so that there

8 See Appendix 1 for more details on the construction of these series. 
is really no difference among the various possible decompositions. Appendix 2 discusses these issues in detail, and explains how we calculate the drift, variance and meansquared errors.

The decompositions are presented graphically. Figure 1 shows the mean-squarederror decomposition ${ }^{9}$ using all 400 months of the data set. So, we can calculate meansquared-errors up to a horizon of 398 months. The horizon appears on the horizontal axis of all graphs. The graph is the fraction of the mean-squared error of $q_{t+n}-q_{t}$ accounted for by the mean-squared error of the traded goods component, $x_{t+n}-x_{t}$.

As was mentioned in the introduction, we might expect, based on a sticky-price view of the world, that $\mathrm{x}_{\mathrm{t}}$ would be larger at short horizons. So, the lines in the graph would perhaps start near one, but should decline toward zero. It should be noted that at very long horizons, very few observations are used in the calculations. So, we should not put too much emphasis on the decomposition at the longest horizons.

Figure 1 is striking, and it does not show what one would expect. With the exception of Canada, virtually $100 \%$ of the mean-squared error of real exchange rate changes for the U.S. are accounted for by movements in the traded goods component at all horizons. The relative price of non-traded goods accounts for none of the movement, even at very long horizons.

The Canadian-U.S. real exchange rate is an exception. At short horizons, traded goods account for over $95 \%$ of the movement, but then, as expected, their importance drops: to about $60 \%$ at fifteen year horizons. But then, unexpectedly, the traded goods component begins to be more important again, and rises up to near $100 \%$ at horizons longer than 20 years. Recall, however, that the longer horizon numbers are less reliable (although 158 observations are available here to calculate 20-year mean-squared-errors.)

Figure 2 shows the fraction of the variance (rather than the mean-squared error) of

9 Using the formula from equation (A.2.5) in Appendix 2. 
changes in the real exchange rate that are attributable to the traded goods component, $\mathrm{x}_{\mathrm{t}} \cdot{ }^{10}$ The message is exactly the same as in Figure 1.

At horizons up to three years, the variance is over $95 \%$ of the mean-squared error, except for the case of Japan. For Japan, it starts near $100 \%$, but the drift becomes important in the mean-squared error fairly rapidly. For horizons beyond eight years, the drift accounts for more than half the mean-squared error in Japan. The drift becomes more important at longer horizons for Germany and France as well, but there is not much drift in the real exchange rate of the U.S. relative to Canada or Italy over this period.

Figure 3 shows the fraction of the drift attributable to the traded goods component. ${ }^{11}$ These are straight lines because the decomposition of the drift does not depend on the horizon. For the three countries whose real exchange rate has significant drift relative to the U.S., the traded goods component accounts for roughly $100 \%$ of the drift. This finding might be considered very surprising. Most theories of the real exchange rate would not predict any drift in $x_{t}$, but, in fact, for the U.S. real exchange rate, $x_{t}$ has drifted, and its drift has dwarfed the drift of $y_{t}$.

As Mussa (1986) and others have noted, the behavior of the U.S. real exchange rate has been very different in fixed nominal exchange rate periods and floating nominal exchange rate periods. Specifically, its variance has been much higher in floating episodes. Figures 1-3 use data from both fixed and floating periods for the U.S. One might suspect that the results would look different from just the fixed-rate period, but that is not true. Figure 4 shows the mean-squared-error decomposition for the floating rate period, 1973-1995, and Figure 5 shows the same decomposition for the fixed rate period, 1962-1970. In both cases, at all horizons, nearly all of the movement in the real exchange rate comes from movements in the traded goods component. Indeed, the only

\footnotetext{
10 Using formula (A.2.3) from Appendix 2.

11 Calculated using formula (A.2.1) from Appendix 2.
} 
difference between these graphs and the ones over the entire sample is that the dip at 15-year horizons that appeared for Canada for the whole sample has now disappeared.

The fact that the traded goods component accounts for virtually all of the movement in real exchange rates even when the nominal exchange rate is fixed is reminiscent of the finding of Froot, Kim and Rogoff (1995). Using 700 years of data, they found that the volatility of deviations from the law of one price is no greater in the 20th century under floating exchange rates than it was in previous centuries when the exchange rate was essentially fixed.

\section{Output Prices}

This section uses output price data from the OECD's international sectoral database. Annual price indexes for nineteen categories of output are calculated by dividing nominal output figures by their real counterparts. ${ }^{12}$ De Gregorio, Giovannini and Wolf (1994) classify these sectors as tradable or non-tradable using data on the export share in total production. They conclude that all the commodities are tradable. All services are categorized as non-tradable, except for the transport, storage and communication category. The traded and non-traded price indexes used here are constructed as in De Gregorio, Giovannini and Wolf.

Although data is available for fourteen countries, because of missing observations it was only possible to construct long time series of real exchange rates for seven countries relative to the U.S.: Canada, Germany, Denmark, Finland, France, Japan and

12 The sectors are agriculture; mining; food, beverages, tobacco; textiles; wood and wood products; paper, printing, publishing; chemicals; non-metallic mineral products; basic metal products; machinery, equipment; other manufactured products; electricity, gas, water; construction; wholesale and retail trade; restaurants, hotels; transport, storage, communications; finance, insurance, and real estate; community, social and personal services; government services. 
Norway. The starting dates for this data vary from country to country. In some cases the data start in 1960 (Finland, Germany, the U.S.), in others the data begin as late as 1970 (France, Japan). The U.S. data end in 1989, while for the other countries the data end in 1990.

Figure 6 shows the mean-squared-error decomposition using all of the data. The pictures tell almost exactly the same story as Figure 1 tells using consumer price data. At all horizons, for all countries with the exception of Canada, virtually $100 \%$ of the mean-squared-error of real exchange rate changes is accounted for by the mean-squarederror of the traded goods component, $x_{1}$. There is no tendency for this component to become less important as the horizon lengthens.

Just as we saw in the case of the CPI data, for Canada the traded goods share accounts for a large share of the real exchange rate movements at short horizons: over $80 \%$ of one-year changes. This drops to around $50 \%$ at 16 -year horizons, but then begins to rise again. Of course, very few observations are used to calculate the longer-horizon numbers.

It is also the case that the variance decompositions and drift decompositions are the same as with the CPI data. At all horizons, all of the variance is attributable to the traded goods component. For all countries that have experienced a significant drift in the real exchange rate relative to the U.S. (which is all but Canada), all of the drift is accounted for by the drift in the trade goods component.

Figure 7 shows the mean-squared error decomposition for the years 1973-1989: the floating nominal exchange rate period. For all countries except Canada, the traded goods component accounts for over $95 \%$ of the mean-squared-error of real exchange rates at all but the longest horizons (for which the numbers are very unreliable). For Canada this fraction is around $85 \%$ for all horizons. Note that, as with the CPI data, the dip in this fraction that occurs using the whole sample at 15-16 years disappears when using 
only the floating-episode data.

There are too few observations from the fixed exchange rate period to construct decompositions. One interesting possibility is to use data for the real exchange rate for Germany relative to EMS partners during the period in which the ERM was in effect. The top row of Figure 8 shows the mean-squared-error decomposition for the franc/mark and lira/mark real exchange rates from March 1979 to June 1993 using the CPI data, while the lower row shows the MSE decomposition using the output price data for the franc/mark real exchange rate from 1979 to 1990 . In fact, both nominal exchange rates experienced realignments, particularly the lira/mark.

For the CPI data, virtually all of the mean-squared error in both cases is accounted for by traded goods prices. For the output prices, that is not true. At short horizons, $x_{t}$ accounts for about $90 \%$ of the movements of the real franc/mark rate, but this fraction falls to about $50 \%$ at the five-year horizon before rising again. This graph should be interpreted with extreme caution, however, since it was constructed using very few data points.

It is important to note that for the U.S. real exchange rate, the CPI and output price data reach the same conclusion, which is that the relative price of non-traded goods is not at all useful in accounting for real exchange rate changes. The results for the CPI data do not appear to be a result of the fact that consumer prices measure the price of both the good and the service that brings the good to market. The marketing service is probably much less important in the output price data.

\section{Personal Consumption Expenditure Deflators}

This section uses data from national income accounts for personal consumption expenditures. The price indexes are constructed by dividing nominal consumption 
experditures by real consumption expenditures. The traded goods price index is the deflator for personal consumption expenditure on commodities, while the non-traded index is for personal consumption expenditure on services. This is the categorization used by Stockman and Tesar (1995) for this data. All data are quarterly. Data for Canada, France, Italy, Japan, Sweden and the United States are from the OECD, while U.K. data are from country sources. All data are taken from Datastream. The data start in the first quarter of 1970 (except for Sweden, which starts in the first quarter of 1980.)

In contrast to all of the other price data used in this study, these prices are seasonally adjusted. This is likely to make the traded goods component, $x_{t}$, relatively more important in explaining very short-term movements in $\mathrm{q}_{\mathrm{i}}$. Seasonal adjustment tends to smooth the price series over short intervals. But $x_{t}$ also contains the nominal exchange rate, which is not seasonally adjusted, so $x_{t}$ will be relatively more volatile.

Figure 9 displays the MSE decomposition. Again, for all real exchange rates (with the exception of the pound/dollar rate) at all horizons, the traded goods component accounts for essentially all of the movement in the real exchange rate. For the pound/dollar rate, $x_{1}$ accounts for over $95 \%$ of the movement out to 13 years. The fraction tails off a bit to around $75 \%$ at the 16-year horizon before increasing again.

The reason the U.K. is different is that just about half of the squared drift in this real exchange rate is accounted for by the non-traded goods component, $y_{t}$. At the 16-year horizon, the squared drift component of the real exchange rate for the U.K. accounts for about $50 \%$ of the MSE. So, the $x_{t}$ component ends up accounting for only $75 \%$ of the MSE of the real exchange rate at this horizon, as opposed to well over $95 \%$ for the other exchange rates.

For all of the exchange rates including the pound, virtually $100 \%$ of the variance is accounted for by the variance of $x_{t}$ at all horizons.

The general implications from this data are the same as from the CPI data and the 
output price data: The non-traded goods price component has accounted for almost none of the movement of U.S. real exchange rates, even at long horizons.

\section{Producer Price Index}

This section uses the overall producer price index as an index of traded goods prices. The traded goods component, $x_{t}$, is constructed as

$$
x_{t}=s_{t}+\ln \left(P P I_{t}^{*}\right)-\ln (P P I) \text {. }
$$

The non-traded component, $y_{t}$, is calculated as

$$
\mathrm{y}_{t}=\ln \left(\mathrm{CPI}_{t}^{*}\right)-\ln \left(\mathrm{PPI}_{\mathrm{t}}^{*}\right)-\left(\ln (\mathrm{CPI})-\ln \left(\mathrm{PPI}_{\mathfrak{\nu}}\right)\right)
$$

The data come from the International Financial Statistics database of the IMF, available on Datastream. It is monthly, not seasonally adjusted data that begins in January 1972 and ends in mid-1995 for seventeen countries: Austria, Belgium, Canada, Denmark, Finland, Germany, Greece, Italy, Japan, the Netherlands, Norway, Portugal, Spain, Sweden, Switzerland, the U.K. and the U.S.

This dataset has the advantage that it covers many more countries than any of our others. However, there are at least four problems with this data that seriously damage its worth:

1) Using the aggregate PPI as a measure of traded goods prices is crude. Clearly, some output is non-traded. Indeed, in section 3, we used only producer price data (from a different source), and classified some sectors as tradable and some as non-tradable.

2) In practice the most serious problem is that, in contrast to our other data, the measures of traded goods prices and non-traded goods prices come from different surveys. What this means is that prices for similar goods might be measured in different ways in the two indexes. The PPI and CPI measures, for example, may have different methods of averaging recordings of disparate prices for the same good, they may survey different 
locations, they may handle changes in quality differently, etc. There is no attempt to reconcile differences, as there would be when prices are all from the same source. 3) If the consumer price index were a geometric average of traded goods prices (in this case, the PPI), and non-traded goods prices, with constant weights, then the measures of $x_{t}$ and $y_{t}$ from equations (2) and (3) are algebraically equivalent to the measures from equation (1). But, the CPI is not constructed this way. Even if the PPI is a good measure of traded goods prices, it may not be the case that $y_{1}$ as defined by equation (3) is a reasonable approximation to the relative non-traded goods price we are interested in. The problem here is that we do not have a separate measure of non-traded goods prices.

4) The comovements between $x_{1}$ and $y_{1}$ were small for all of our other price series. But for this measure $x_{t}$ and $y_{t}$ have a strong negative relation. That is probably related to the fact that $\ln \left(\mathrm{PPI}_{1}^{*}\right)-\ln \left(\mathrm{PPI}_{\mathcal{V}}\right)$ appears with a positive sign in $\mathrm{x}_{1}$ and a negative sign in $y_{1}$. There is little ambiguity in the decomposition when the comovements are small. But, when comovements in $x_{1}$ and $y_{1}$ account for a lot of the movement in $q_{1}$, then the amount of movement in $q_{t}$ that we attribute to $x_{t}$ depends heavily on how we treat comovements.

Figure 10 displays the decomposition of the MSE given by equation (A.2.6). We note that it is possible for $x_{t}$ to account for more than $100 \%$ of the MSE of $q_{1}$ under this formula if the comovements of $x_{1}$ and $y_{1}$ are sufficiently negative. This calculation arbitrarily classifies half of the comovements as being caused by movements in $x_{1}$, and the other half as coming from movements in $y_{1}$.

The pictures in Figure 10 are mixed. For some countries -- Greece, Italy, Portugal, and perhaps the U.K., Austria and Japan -- the results are the same as for our previous measure of prices. Nearly all of the movement in real exchange rates is accounted for by the traded goods price component. 
$\mathrm{C}$ in the other hand, for three of the countries -- Germany, the Netherlarids and Canada -- the real exchange rate decomposition follows the pattern that sticky-price theory would predict. That is, traded goods account for almost all of the short-run movement, but the non-traded component accounts for most of the long-run movements.

For the other seven countries -- Belgium, Finland, Spain, Sweden, Denmark, Norway, and Switzerland -- the non-traded goods component is important at some horizons, but there is no discernible pattern in the MSE decompositions.

Unfortunately, the decompositions in these graphs depend heavily on our choice of attributing exactly half of the co-movements of $x_{t}$ and $y_{t}$ to each component. All of these graphs change substantially when we alter this fraction. So, we must not take the decompositions presented in this section too seriously.

\section{The Real U.S./Japan Exchange Rate}

The non-traded goods price component, $y_{t}$, accounts for little movement in the real exchange rate at any horizon. Here we shall pay special attention to the real exchange rate between the U.S. and Japan.

Figure 11 plots real CPI and PPI exchange rate indexes with monthly data beginning in January 1972. For the CPI exchange rate, the dollar has depreciated in real terms by about $180 \%$, while in PPI terms the real depreciation has been about $100 \%$. There has also been dramatic short-term and medium-term volatility. Between 1977 and 1982, the dollar gained about 80 points on the CPI real exchange rate index, and about 50 on the PPI real exchange rate index. Large gains for the dollar were also recorded between 1988 and 1990.

Figure 12 displays graphs of the price of non-traded goods relative to traded goods in Japan and the U.S. for the four measures of prices that were used in sections 1-4. 
Consider the first graph, in the upper left-hand corner of Figure 12 for consumer prices. We see from this graph that non-traded goods prices have risen steadily relative to traded goods prices in Japan since 1970. This would be consistent with the non-traded goods explanation for the real appreciation of the yen. From equation (1), as relative non-traded goods prices increase in Japan, the real yen rises. But, there are four reasons why this movement does not end up accounting for much of the movement in the real exchange rate:

1) The increase in the relative price of non-traded goods in Japan was about $40 \%$ during this period, but the appreciation of the CPI real exchange rate was $180 \%$.

2) There are no large downswings in the relative price of non-traded goods in Japan, but there were periods of dramatic real depreciation for the yen.

3) In equation (1), the effect of non-traded goods prices is diminished in the real exchange rate calculation, because it is multiplied by the share of non-traded goods in Japanese consumption, which is calculated to be about 31 .

4) The most important reason why the non-traded goods component, $y_{t}$, can explain so little of the real exchange rate movement is that it subtracts off $\alpha\left(\mathrm{p}_{1}^{\mathrm{N}}-\mathrm{p}_{\mathrm{t}}^{\mathrm{T}}\right)$ from


(times their consumption share) from the relative price of non-traded goods in Japan (times their consumption share). It is the relative relative price of non-traded goods that matters. As the graph in Figure 12 shows, the relative price of non-tradables in the U.S. has closely mirrored the relative price of non-tradables in Japan. Their movements cancel each other out.

The graphs for the relative prices of non-traded goods constructed from the OECD output prices (labeled "Producer Prices" in Figure 12) and for the deflator for personal consumption expenditures (labeled "GNP Deflator Price Indexes" in Figure 12) give a similar perspective. Movements of non-traded goods prices in Japan are generally offset 
by movements of non-traded goods prices in the U.S.

The final graph in Figure 12, which plots the ratio of the CPI to the PPI in each country is a little different. In Japan, since 1972, the CPI has risen by $60 \%$ relative to the PPI, while in the U.S. the increase in the CPI/PPI ratio has been less than $20 \%$. The movements in these prices is still not enough to account for much of the real exchange rate movement (as Figure 10 documents), but it does appear to give more credence to the non-traded goods price avenue than any of the other measures.

One potential problem with our measures of traded-goods prices is that there are extensive producer services -- distribution, retailing, advertising, etc. -- whose costs are included in the traded goods price. Since these marketing services are largely nontradable, this hypothesis could revive the possibility that the relative price of nontradables can account for much of the real exchange rate movement. It is possible that the rapid increase in the price of marketing services in Japan accounts for the real appreciation of the yen. This line of reasoning would argue that it appears that traded goods prices account for much of the the real CPI exchange rate movements, but in fact our measure of traded goods contains a large non-tradable marketing component. According to this argument, the fluctuations in the relative traded goods prices, $\mathbf{x}_{t}$, is really reflecting fluctuations in relative marketing costs.

Actually, we have already seen one bit of evidence that weighs in against this hypothesis. Even when we examine the OECD output prices in section 3, we find that the traded goods component accounts for all of the real exchange rate movements at all horizons. The marketing and distribution prices should not be an important component of these output prices.

More direct evidence is reported in Figure 13. Here we graph prices of marketing services in Japan relative to the CPI for all goods. The data are monthly, beginning in January 1985, not seasonally adjusted prices of corporate services available on 
Datastream. The service prices graphed are for all services; finance and insurance; real estate services; transportation services' leasing and renting; and, information services. In fact, data is available for another 30 categories of corporate services, but these are not graphed because of space considerations.

If the prices of these services are to explain the real appreciation of the yen, and the large swings in the yen's real value, then they must rise relative to the overall CPI during this period and experience wide swings. In fact, most of these prices fall relative to the CPI. Only six of the thirty-six increase noticeably against the CPI -real estate services, other services, building maintenance, civil engineering and construction, judicial and accounting services, and industrial waste disposal. The index for all corporate services holds steady relative to the CPI over the entire period, as can be seen in Figure 13.

So, the prices of marketing services do not move significantly and do not appear to be able to account for the real exchange rate movements.

\section{Bias in Traded Goods Measurement}

At several points above we have discussed the possibility that the traded goods prices are mismeasured because they may contain a non-traded component. We have just seen that the price of marketing services in Japan do not show any dramatic movement that is comparable to the swings in the real exchange rate. But, our measure of the meansquared error of the price of non-traded to traded goods could be significantly understated even if there were no dramatic movements in the price of non-traded marketing services.

Suppose, in fact, that non-traded marketing services prices are perfectly correlated with our measure of other non-traded goods prices, $p_{1}^{N}$. But, suppose our 
measure of traded goods prices, $\mathrm{p}_{\mathrm{t}}^{\mathrm{T}}$, is actually a weighted average of the non-traded goods price, and the price of goods that are truly traded, $\mathrm{p}_{1}^{\mathrm{c}}$ :

$$
\mathrm{p}_{t}^{T}=\gamma \mathrm{p}_{\mathrm{t}}^{\mathrm{N}}+(1-\gamma) \mathrm{p}_{\mathrm{i}}^{\mathrm{C}} \text {. }
$$

Likewise, in the foreign country, $\gamma$ is the weight that non-traded marketing services take in our measure of traded goods prices.

In this case, the weight that non-traded goods prices receive in the overall price index domestically is actually $\alpha+\gamma(1-\alpha)$, while we have taken it to be just $\alpha$. The true measure of $y_{1}$ that we would like is

$$
\hat{y}_{t} \equiv[\beta+\gamma(1-\beta)]\left(p_{1}^{N^{*}}-p_{1}^{C^{*}}\right)-[\alpha+\gamma(1-\alpha)]\left(p_{1}^{N}-p_{1}^{C}\right) \text {. }
$$

To get an idea of the sort of bias that we introduce when we use $y_{t}$ instead of $\hat{y}_{t}$ as the element of the real exchange rate attributable to relative price movements, note that we can rewrite $y_{t}$ as:



While the domestic relative price of non-traded goods should be getting a weight of $\alpha+\gamma(1-\alpha)$ as in the expression for $\hat{y}_{t}$ (and $\beta+\gamma(1-\hat{\beta})$ for foreign goods), we are actually giving them a weight of $\alpha(1-\gamma)$ (and $\beta(1-\gamma)$ for foreign goods) when we use $y_{t}$ as our measure. This biases downward the importance of the relative price of non-traded goods. When $\gamma$, the share of non-traded marketing services in our measure of traded goods prices, is large, the bias could be severe.

The problem, of course, is that we do not measure $\mathrm{p}_{1}^{\mathrm{c}}$ and $\mathrm{p}_{1}^{\mathrm{C}^{*}}$ directly. We could, however, construct measures by using the relation:

$$
\mathrm{p}_{\mathrm{t}}^{\mathrm{C}}=\frac{1}{\Gamma-\gamma}\left(\mathrm{p}_{\mathrm{t}}^{\mathrm{T}}-\gamma \mathrm{p}_{\mathrm{i}}^{\mathrm{N}}\right)
$$

We do not know the value of $\gamma$, but we can experiment with different levels.

Before proceeding in this direction, we note that this calculation generates a series for $\hat{y}_{t}$ that is probably too volatile. $p_{1}^{N}$ is not an accurate measure of the price of marketing services. Suppose that $\mathrm{p}_{\mathrm{t}}^{\mathrm{N}}$ measures the price of marketing services, $\mathrm{p}_{\mathrm{t}}^{\mathrm{M}}$, 
ith measurement error $u_{\mathrm{t}}$ :

$$
\mathrm{p}_{\mathrm{t}}^{\mathrm{MS}}=\mathrm{p}_{\mathrm{t}}^{\mathrm{N}}+\mathrm{u}_{\mathrm{t}} \text {. }
$$

Ideally, the relative price of non-traded to traded goods, $\hat{y}_{t}$, would be measured as a weighted average of the relative prices of $p_{t}^{N}$ and $p_{t}^{M S}$ to $p_{1}^{C}$ :

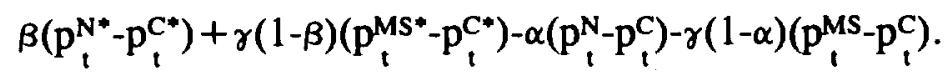

But, by introducing the measurement error into $\mathrm{p}_{t}^{\mathrm{MS}}$, our measure of $\hat{y}_{\mathrm{t}}$ is actually:

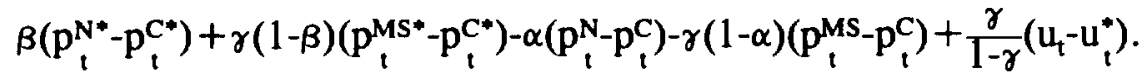

This introduces volatility into our measure of $\hat{y}_{t}$ that can be substantial when $\gamma$ is large.

With this caveat in mind, we note that following the procedure outlined above for calculating $\mathrm{p}_{\mathrm{t}}^{\mathrm{c}}$ (and $\mathrm{p}_{\mathrm{t}}^{\mathrm{c}}$ ) is equivalent to rewriting $\hat{\mathrm{y}}_{\mathrm{t}}$ in terms of variables we can measure:



So, we can take our previous measure of $y_{t}$ and simply increase the weights from $\beta$ and $\alpha$ to $\beta+\frac{\gamma}{\Gamma-\gamma}$ and $\alpha+\frac{\gamma}{\Gamma-\gamma}$.

Figure 14 reproduces the mean-squared error decomposition using consumer price indexes over the floating exchange rate period that we presented in Figure 4. However, here the weights on the relative non-traded goods prices are increased by setting $\gamma$ equal to $1 / 3$ (which means that we add 0.5 to $\beta$ and $\alpha$ ). ${ }^{13}$ This choice of $\gamma$ is arbitrary, and is meant to reflect the situation when the share of marketing services in final goods prices is $1 / 3$. We see that the fraction of the MSE attributable to the traded goods component, $x_{t}$, is lower than in Figure 4, as expected. However, it is still very large -- over $90 \%$

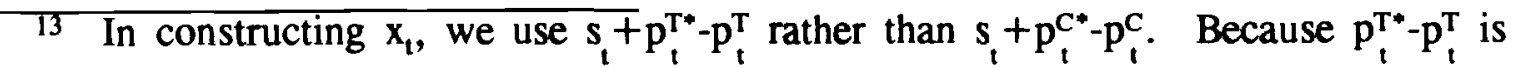
less volatile than $p_{1}^{c^{*}}-p_{t}^{c}$, Figures 14 and 15 bias down the contribution of the $x_{1}$ component. 
at all horizons for all currencies except for the Canadian dollar. ${ }^{14}$

Figure 15 uses a value of $\gamma$ equal to $2 / 3$, which means that we add 2.0 to the values of $\beta$ and $\alpha$ used in Figure 4. This probably greatly overcompensates for the bias that occurs from our mismeasurement of traded goods prices. Both because of the measurement problems introduced into our measure of $\hat{y}_{t}$ that overstate its volatility (as discussed above), and because the marketing share is unlikely to be as large as $2 / 3$, the numbers represented in Figure 15 are probably a lower bound on the share of the MSE accounted for by fluctuations in the traded goods price component. Even so, $x_{t}$ accounts for a large share of the MSE at all horizons for most of the currencies.

We conclude that even taking into account the possibility that there is a nontraded component in our measure of traded goods prices, the relative price of non-traded goods contributes little to the movements in real exchange rates.

\section{Conclusions}

So far, we have said nothing to explain why the movements in the relative price of traded goods is so important for the real exchange rate. One possibility is terms of trade movements. If there are fluctuations in the relative prices of goods which comprise the traded goods price indexes, and if the weights these goods receive are different in the U.S. and the foreign price index, then the relative traded goods price indexes will fluctuate.

It is difficult to investigate this avenue with our data, since we cannot disaggregate our traded goods price indexes much. With our consumer price data, the indexes are composed from two sub-indexes: for food, and for all goods not including

14 Note that for France, at the longest horizons, the fraction falls off below $95 \%$, but the MSE calculations at these horizons use few observations. 
food. For our OECD output price data, the traded goods price index is comprised of subindexes for twelve categories of goods and services. None of the other traded goods price indexes can be disaggregated.

Appendix 3 reports the outcome of investigating the terms of trade hypothesis for the CPI and OECD output price indexes. There, we find that this theory explains very little. The chief reason is that the weights of the sub-categories in the overall price index are not too different across countries. So, there may be a lot of volatility in relative price movements among the sub-categories, but it does not have much of an effect on the overall price index.

It should be noted that all of the real exchange rates examined in this study are for high-income countries (and usually relative to the U.S.). As Table 3 of Rogoff (1995) demonstrates, the behavior of real exchange rates for low-income countries might be very different. The absolute purchasing power of the currency of low-income countries is much higher than that for high-income countries, although within the two groups there seems to be little relationship between income and purchasing power. It seems likely that the disparity between low-income and high-income countries' purchasing powers reflects differences in the relative prices of non-traded goods.

It is tempting to attribute the movements in the traded goods price indexes to failures of the law of one price. That conclusion would be consistent with the findings of a number of recent studies. ${ }^{15}$ However, there are many issues to be resolved in that area: What determines export prices to different regions from the same country? How important is pricing to market in determining real exchange rate movements? What systematic relationship is there between the price of a good at the port and at the consumer outlet? To what extent does the degree of product differentiation and the

15 Engel (1993), Rogers and Jenkins (1995), Knetter (1994), Engel and Rogers (1994), Froot, Kim and Rogoff (1995). 
competitiveness of the industry determine differences in prices between locations? What role does nominal price stickiness play, and how is it related to these other questions? These are important areas of research that are beyond the scope of this paper. The key to understanding real exchange rate movements may lie in the answers to these questions. But, the evidence of this paper suggests that the relative price of non-traded goods has little import for understanding U.S. real exchange rate movements. 


\section{Appendix 1}

\section{Data}

The nominal exchange rates used in all sections are spot rates measured in U.S dollars per unit of foreign currency. Period average exchange rates from the IMF's International Financial Statistics database are used for the 1972 - 1995 sample range. These are averages of daily rates within a given time period, and they are available from Datastream's IMF series. Period average exchange rates from Datastream's National Government series are used for the 1969 - 1971 sample range, while end-of-period exchange rates from Datastream's OECD series are used for the 1960 - 1969 sample range. In general, there should be very little difference between period-average and end-of-period U.S. dollar exchange rates from 1960 through 1971.

Section 1 of the paper utilizes consumer price index data from Canada, France, Germany, Italy, Japan and the U.S. to construct measures of traded and non-traded goods prices for those six countries. The data used are monthly series reflecting the cost to consumers of all items (AI), all goods less food (AGLF), food (F), services less rent (SLR) and rent (R). All of these series, which are drawn from the OECD component of Datastream's Economic Database, are seasonally unadjusted and run from January 1972 through March 1995.

Geometric weights for each of the four components of the all items series were estimated from logarithmic regressions of the form

$$
\Delta(\text { ai-r })=\phi_{1} \Delta(\text { aglf-r })+\phi_{2} \Delta(\mathrm{f}-\mathrm{r})+\phi_{3} \Delta(\text { (slr-r) }+\varepsilon,
$$

where $\Delta()$ is the first difference operator, and lower case letters are used to denote natural logarithms. The geometric weight for rent is computed residually as $1-\phi_{1}-\phi_{2}-\phi_{3}$. The regressions are run in differenced form so as to lessen the effects of the high 
degree of multicollinearity among the CPI component series. Indexes for each country measuring the prices of traded and non-traded goods are constructed (in logarithmic form) as:

$$
\begin{aligned}
& \mathrm{p}^{\mathrm{T}}=\frac{\phi_{1}}{\phi_{1}+\phi_{2}} \text { (aglf) }+\frac{\phi_{2}}{\phi_{1}+\phi_{2}}(\mathrm{f}), \\
& \mathrm{p}^{\mathrm{N}}=\frac{\phi_{3}}{\phi_{3}+\phi_{4}}(\text { slr })+\frac{\phi_{4}}{\phi_{3}+\phi_{4}}(\mathrm{r}),
\end{aligned}
$$

Finally, the weight for non-traded goods, which is used to decompose each real exchange rate into its two components $(q=x+y)$, is computed for each country as $\phi_{3}+\phi_{4}$.

Section 2 of the paper uses nominal and real output measures for 19 economic sectors in eight different countries to construct traded and non-traded goods price indexes for each of those countries. The annual output data is taken from the OECD's international sectoral database. The sample range (i.e. the range of years over which unbroken series are available for all 19 sectors listed in footnote 11) for each country is shown below.

\begin{tabular}{|l|l|l|}
\hline Country & Start & End \\
\hline Canada & 1961 & 1989 \\
Germany & 1960 & 1990 \\
Denmark & 1966 & 1990 \\
Finland & 1960 & 1990 \\
France & 1970 & 1990 \\
Japan & 1970 & 1990 \\
Norway & 1962 & 1988 \\
U.S. & 1960 & 1989 \\
\hline
\end{tabular}

Sectoral price indexes for each country are constructed as the ratio of nominal to real output, using data from the earliest year it is available through 1989. Twelve sectors are classified as traded, while the other seven sectors are classified as nontraded, as outlined in section 2 . The traded goods price index for a given country is 
computed year by year as a simple weighted average of the price index values for the twelve traded goods sectors in that country. Similarly, the non-traded goods price index is a weighted average of the price indexes for the seven non-traded sectors. Fixed weights for each of the twelve traded sectors are computed as the sample average ratio of nominal sectoral output to total nominal output of all traded goods. The same procedure is also used to compute non-traded sector weights. Finally, the overall weight for a given country's non-traded goods is the sample average ratio of nominal non-traded output to nominal output for all 19 sectors combined.

Personal consumption expenditures data from Datastream's OECD Quarterly Accounts series are used to construct traded and non-traded goods price indexes for Canada, France, Italy, Japan, Sweden and the U.S. These indexes are used in section 3 of the paper. The data series for Canada, France, Italy and the U.S. range from the first quarter of 1970 through the fourth quarter of 1994, while the series for Japan (1970:11994:2) and Sweden (1980:1-1994:2) are somewhat shorter. The OECD data provides separate series for nominal and real commodities expenditures and for nominal and real services expenditures. Price indexes are computed as the ratio of nominal to real expenditures, with commodities classified as traded goods and services classified as non-traded goods. The expenditures data available for Japan and Sweden was seasonally unadjusted, while the data for Canada, France, Italy and the U.S. was seasonally adjusted. In order to eliminate this inconsistency, a multiplicative seasonal adjustment was applied to the price indexes computed for Japan and Sweden. This transformation had only a very slight impact on the price indexes for these two countries, since nominal and real expenditures (on either commodities or services) exhibit nearly identical seasonal patterns. In other words, most of the seasonal variation in expenditures is driven by seasonal variation in quantities rather than prices. Price indexes are also constructed for the U.K., using 
nominal and real expenditures on durable goods, non-durable goods and services from Datastream's National Government series. These series are seasonally adjusted and range from the first quarter of 1970 through the fourth quarter of 1994 . The first two categories of expenditures are classified as traded, while services are again classified as non-traded. Separate price indexes are calculated as the ratio of nominal to real expenditures within each category, and a traded goods price index is calculated as a weighted combination of the durables and non-durables price indexes. The weight for durables is the sample average ratio of nominal expenditures on durable goods to nominal expenditures on all goods (durables + non-durables). Subtract this fixed weight from one to get the weight for non-durables. Finally, the share of non-traded goods in an overall U.K. consumption deflator price index is the sample average ratio of nominal services expenditures to total nominal expenditures (durables + non-durables + services).

Section 4 uses overall producer and consumer price indexes (along with the appropriate nominal exchange rate series) to consiruct the traded and non-traded components of the real exchange rate between the U.S. and sixteen other developed countries. Monthly, not seasonally adjusted, price indexes (PPI and CPI) for the seventeen countries listed in section 5 are taken from Datastream's IMF series. Each of these 34 series begins in January 1972, and all but four of them continue at least through February 1995. The exceptions are: Belgium (through December 1992), Italy (November 1993), Portugal (December 1986), and Switzerland (September 1993). All available data is used in computing real exchange rate component series for each country relative to the U.S., according to the formulas given in equations (2) and (3).

The U.S./Japan real exchange rate indexes plotted in Figure 11 are computed using monthly, not seasonally adjusted, series from the IMF's International Financial 
Statistics database. This database is available from Datastream (IMF series). Specifically, the consumer and producer price index series for the U.S. and Japan and the monthly-average U.S. I Japan nominal exchange rate series are used to construct the two real exchange rate indexes, which are normalized to equal 100 in January 1972 . Figure 12 presents four different graphs of the non-traded to traded goods price ratios in the U.S. and Japan, with each graph using a different measure of these price indexes. The four different price measures correspond to the indexes constructed for each of the four preceding sections (1-4) of the paper. All of the price ratios are normalized to start from a value of 100 (in 1970 or 1972 , depending on the measure). Figure 13 presents graphs of the price of a particular category of Japanese corporate services relative to the overall consumer price index for Japan. Each of these relative price measures is normalized to equal 100 in January 1985 , which is the initial observation for the Japanese corporate service price indexes. These indexes are not seasonally adjusted, and they were available through May 1995 from Datastream's National Government series. The monthly measure of consumer prices in Japan is taken from Datastream's IMF series.

Data is available for prices of a large number of corporate services in Japan, some of which are not graphed in Figure 13. The service prices include prices for all services; finance and insurance; banking charges; casualty insurance services; real estate; transportation; railway freight; road freight; outer sea freight; inner sea freight; harbor transportation; international air freight; domestic air freight; railway passenger transportation; road passenger transportation; air passenger transportation; storage; packaging; highway tolls; information services; communications; mailing; domestic telecommunications; international telecommunications; advertising services; advertisements on broadcasts; other advertisements; leasing and renting; leasing; renting; other services; building maintenance; civil engineering and construction; judicial and accounting services; industrial waste disposal; and, sewage systems. 
The following table gives the weight that non-traded goods receive in the price index for each country used in sections 1-3:

\begin{tabular}{|l|l|l|l|}
\hline Country & Section 1 & Section 2 & Section 3 \\
\hline Canada & 0.381656 & 0.611008 & 0.311948 \\
Denmark & --- & 0.652375 & --- \\
Finland & -- & 0.550627 & --- \\
France & 0.267315 & 0.626133 & 0.277062 \\
Germany & 0.283371 & 0.525382 & --- \\
Italy & 0.224286 & -- & 0.245615 \\
Japan & 0.309726 & 0.591941 & 0.326304 \\
Norway & --- & 0.556130 & --- \\
Sweden & --- & -- & 0.265376 \\
U.K. & -- & -- & 0.393785 \\
U.S. & 0.458829 & 0.644987 & 0.335406 \\
\hline
\end{tabular}




\section{Appendix 2}

\section{Methods for Decomposing Real Exchange Rate Movements}

First consider the drift. For a sample size of $\mathrm{N}$, the average $n$-period drift is computed as

$$
\begin{aligned}
& \operatorname{Mean}\left(\mathrm{q}_{\mathrm{t}}-\mathrm{q}_{\mathrm{t}-\mathrm{n}}\right)=n \overline{\Delta \mathrm{q}} \text {, where } \\
& \overline{\Delta q}=\frac{1}{N-1}\left(\mathrm{q}_{N}-\mathrm{q}_{1}\right) .
\end{aligned}
$$

In words, $\overline{\Delta q}$ is the average one-period change in $q_{l}$. To get the average $n$-period change, we take $\mathrm{n}$ times the average 1-period change. ${ }^{16}$

We want to find the amount of the squared drift in $q_{t}$ attributable to $x_{t}$. One way to do this is to take:

$$
\frac{\left(\operatorname{Mean}\left(x_{t}-x_{t-n}\right)\right)^{2}}{\left(\operatorname{Mean}\left(x_{t}-x_{t-n}\right)\right)^{2}+\left(\operatorname{Mean}\left(y_{t}-y_{t-n}\right)\right)^{2}} .
$$

The denominator of equation (2) does not equal the average squared drift in $q_{t}$. Instead, we have

$$
\left(\operatorname{Mean}\left(q_{t}-q_{t-n}\right)\right)^{2}=\left(\operatorname{Mean}\left(x_{t}-x_{t-n}\right)\right)^{2}+\left(\operatorname{Mean}\left(y_{t}-y_{t-n}\right)\right)^{2}+2 \operatorname{Mean}\left(x_{t}-x_{t-n}\right) \operatorname{Mean}\left(y_{t}-y_{t-n}\right) .
$$

In any decomposition, the puzzling issue is how to deal with comovements. One simple way (since this is only an accounting exercise) is to attribute half the comovements to $x$, and the other half to $y$. So, an alternative way to calculate the amount of squared drift in $q_{t}$ attributable to $x_{t}$ is:

$$
\frac{\left(\operatorname{Mean}\left(x_{t}-x_{t-n}\right)\right)^{2}+\operatorname{Mean}\left(x_{t}-x_{t-n}\right) \operatorname{Mean}\left(y_{t}-y_{t-n}\right)}{\left(\operatorname{Mean}\left(q_{t}-q_{t-n}\right)\right)^{2}}
$$

16 This would be the MLE of the drift if $q_{t}$ followed a random walk with drift. 
The standard calculation of the sample variance tends to drop rapidly to zero as $n$ gets large relative to $N$. One way to understand the problem is that if $q_{t}$ followed a random walk with drift, this measure has extreme small-sample bias for large $n$. In that circumstance, a measure of the variance of $q_{1}$ that would be unbiased in small samples is: 17

$$
\operatorname{Var}\left(q_{t}-q_{t-n}\right)=\frac{N}{(N-n-1)(N-n)} \sum_{j=1}^{N-n}\left(q_{j+n}-q_{j}-n \overline{\Delta q}\right)^{2} .
$$

We will use this formula to calculate all variances.

One measure of the fraction of $\operatorname{Var}\left(\mathrm{q}_{t}-\mathrm{q}_{\mathrm{t}-\mathrm{n}}\right)$ accounted for by $\operatorname{Var}\left(\mathrm{x}_{\mathrm{t}}-\mathrm{x}_{\mathrm{t}-\mathrm{n}}\right)$ is:

$$
\frac{\operatorname{Var}\left(x_{t}-x_{t-n}\right)}{\operatorname{Var}\left(x_{t}-x_{t-n}\right)+\operatorname{Var}\left(y_{t}-y_{t-n}\right)}
$$

As before, there is the issue of how to deal with comovements of $x$ and $y$. Another measure of the portion of the variance of $\operatorname{Var}\left(\mathrm{q}_{\mathrm{t}}-\mathrm{q}_{\mathrm{t}-\mathrm{n}}\right)$ attributable to $\operatorname{Var}\left(\mathrm{x}_{\mathrm{t}}-\mathrm{x}_{\mathrm{t}-\mathrm{n}}\right)$ is:

$$
\frac{\operatorname{Var}\left(x_{t}-x_{t-n}\right)+\operatorname{Cov}\left(x_{t}-x_{t-n}, y_{t}-y_{t-n}\right)}{\operatorname{Var}\left(q_{t}-q_{t-n}\right)} .
$$

The covariance term is calculated with the same small-sample correction as the variance.

We note that the small-sample correction does not matter for decomposition (A.2.3) or (A.2.4), since it cancels out in the numerator and denominator. However, it does make a difference when we calculate the mean-squared error, since we need to add the measure of the variance of the n-difference to the measure of the squared drift of the $n$ difference. As was emphasized in the introduction, these calculations are not meant to be estimates of any underlying population parameters. So, while all of these calculations would be unbiased in small samples if $q_{1}, x_{t}$ and $y_{1}$ followed random walks with drifts, we are not making these corrections in order to get unbiased estimates of moments. Instead, these corrections merely give us a plausible method of adding together the effects of drift and volatility. In practice, without the small-sample correction to

17 See Cochrane (1988) for a demonstration of the unbiasedness of this measure. 
the calculation of the variance, the variance for large $n$ becomes unreasonably small.

We take as our measure of the mean-squared-error of $n$-differences in $q_{t}$ the sum of the variance measure and the square of the drift measure:

$$
\operatorname{MSE}\left(\mathrm{q}_{\mathrm{t}}-\mathrm{q}_{\mathrm{t}-\mathrm{n}}\right)=\operatorname{Var}\left(\mathrm{q}_{\mathrm{t}}-\mathrm{q}_{\mathrm{t}-\mathrm{n}}\right)+\left(\operatorname{Mean}\left(\mathrm{q}_{\mathrm{t}}-\mathrm{q}_{\mathrm{t}-\mathrm{n}}\right)\right)^{2},
$$

and likewise for the mean-squared-errors of $x_{t}$ and $y_{t}$.

The amount of the mean-squared-error of $\mathrm{q}_{\mathrm{t}}-\mathrm{q}_{\mathrm{t}-\mathrm{n}}$ accounted for by $\mathrm{x}_{\mathrm{t}}-\mathrm{x}_{\mathrm{t}-\mathrm{n}}$ can be measured either as

$$
\frac{\operatorname{MSE}\left(\mathrm{x}_{\mathrm{t}}-\mathrm{x}_{\mathrm{t}-\mathrm{n}}\right)}{\operatorname{MSE}\left(\mathrm{x}_{\mathrm{t}}-\mathrm{x}_{\mathrm{t}-\mathrm{n}}\right)+\operatorname{MSE}\left(\mathrm{y}_{\mathrm{t}}-\mathrm{y}_{\mathrm{t}-\mathrm{n}}\right)},
$$

or, taking into account comovements,

$$
\frac{\operatorname{MSE}\left(x_{t}-x_{t-n}\right)+\operatorname{Mean}\left(x_{t}-x_{t-n}\right) \operatorname{Mean}\left(y_{t}-y_{t-n}\right)+\operatorname{Cov}\left(x_{t}-x_{t-n}, y_{t}-y_{t-n}\right)}{\operatorname{MSE}\left(q_{t}-q_{t-n}\right)} .
$$

Because of space considerations, it is impossible to present all of the decompositions (A.2.1)-(A.2.6) for all of the measures of prices. As it turns out, comovements between $x$ and $y$ are insignificant in all cases except when we use the aggregate PPI as the traded goods price index. That is, $\operatorname{Cov}\left(x_{t}-x_{t-n}, y_{t}-y_{t-n}\right)$ is small relative to $\operatorname{Var}\left(\mathrm{q}_{\mathrm{t}}-\mathrm{q}_{\mathrm{t}-\mathrm{n}}\right)$ for this data. Occasionally comovements are an important part of the drift -- Mean $\left(x_{t}-x_{t-n}\right) \operatorname{Mean}\left(y_{t}-y_{t-n}\right)$ is large relative to $\left(\operatorname{Mean}\left(q_{t}-q_{t-n}\right)\right)^{2}$-- but only in those cases where the squared drift in $\mathrm{q}_{\mathrm{t}}-\mathrm{q}_{\mathrm{t}-\mathrm{n}}$ is very small relative to its mean-squared-error. In short, comovements are not important in explaining the overall movement in $\mathrm{q}_{\mathrm{t}}-\mathrm{q}_{\mathrm{t}-\mathrm{n}}$. So, only decompositions (A.2.1), (A.2.3) and (A.2.5) are presented, except when we look at the PPI as the traded goods price index. Moreover, generally only decomposition (A.2.5) is presented. Usually the variance is the dominant part of the mean-squared-error. There are exceptions to this at long-horizons for some currencies. When appropriate, the trend decomposition is discussed even when it is not presented graphically. 


\section{Appendix 3}

\section{Terms of Trade Movements}

In this appendix, we briefly address the issue of why movements in the relative price of traded goods is so large. One possibility is that the law of one price fails. Another possibility, however, is that the traded goods price indexes weight gonds differently in the two countries. Suppose, for example

$$
\begin{aligned}
& \mathrm{p}_{\mathrm{t}}^{\mathrm{T}}=\nu \mathrm{p}_{\mathrm{t}}^{1}+(1-v) \mathrm{p}_{\mathrm{t}}^{2} \text {, and } \\
& \mathrm{p}_{\mathrm{t}}^{\mathrm{T}^{*}}=\eta \mathrm{p}_{\mathrm{t}}^{1^{*}}+(1-\eta) \mathrm{p}_{\mathrm{t}}^{2^{*}} .
\end{aligned}
$$

Even if the law of one price held for each good, so $p_{t}^{j}=s_{1}+p_{t}^{j^{*}}(j=1,2)$, if $v \neq \eta$, then $p_{t}^{T}-s_{t}-p_{t}^{T^{*}}$ will change as $p_{t}^{1}$ moves relative to $p_{t}^{2}$.

One way to gauge how important this issue is would be to recalculate the foreign traded goods price index using U.S. weights, and see if this significantly lowers the mean-squared-error of our measure of $p_{1}^{T}-s_{1}-p_{1}^{T^{* *}}$. If terms of trade movements were all that mattered, and the law of one price held for each good, it should reduce the MSE to zero. We undertook this task, and in fact found that it did not reduce the MSE (or the variance, or the squared drift) in our measure of $p_{t}^{T}-s_{t}-p_{t} T^{*}$. We also tried the opposite tack of calculating the U.S. price index using foreign weights, and also found that it did not have much effect.

As an example, Figure 16 plots the ratio of the MSE of $\mathrm{p}_{t}^{\mathrm{T}}-\mathrm{S}_{\mathrm{t}}-\mathrm{p}_{\mathrm{t}}^{\mathrm{T}^{*}}$ when foreign weights are used in the U.S. price index to the MSE when the U.S. price index uses its own weights. This graph is done using the consumer prices of section 1. It shows the ratio in all cases is close to unity -- there was little effect. If the terms of trade movements were important, this ratio should be close to zero. Likewise, Figure 17 plots the ratio using the output prices from section 2. Again, the effect on the MSE is insignificant -- the ratios are all near one, not zero. 


\section{References}

Asea, Patrick K. and Enrique G. Mendoza, 1994, The Balassa-Samuelson model: A general equilibrium appraisal, Review of International Economics 2, 244-267.

Brock, Philip L., 1994, Economic development and the relative price of nontradables: Global dynamics of the Krueger-Deardorff-Leamer model, Review of International Economics 2, 268-283.

Brock, Philip L. and Stephen J. Turnovsky, 1994, The dependent-economy model with both traded and non-traded capital goods, Review of International Economics 2, 306-325.

Cochrane, John, 1988, How big is the unit root component of GNP?, Journal of Political Economy 96, 893-920.

De Gregorio, Jose; Alberto Giovannini; and Thomas Krueger, 1994, The behavior of nontradable goods prices in Europe: Evidence and interpretation, Review of International Economics 2, 284-305.

De Gregorio, Jose; Alberto Giovannini; and Holger C. Wolf, 1994, International evidence on tradables and nontradables inflation, European Economic Review 6, 1225-1244.

De Gregorio, Jose, and Holger C. Wolf, 1994, Terms of trade, productivity and the real exchange rate, National Bureau of Economic Research working paper no. 4807.

Engel, Charles, 1993, Real exchange rates and relative prices: An empirical investigation, Journal of Monetary Economics 32, 35-50.

Engel, Charles and John H. Rogers, 1994, How wide is the border?, National Bureau of Economics working paper no. 4829.

Engel, Charles and John H. Rogers, 1995, Regional patterns in the law of one price: The roles of geography and currency, University of Washington, working paper.

Froot, Kenneth A. and Kenneth Rogoff, 1994, Perspectives on PPP and long-run real exchange rates, National Bureau of Economics working paper no. 4952.

Froot, Kenneth A., Michael Kim and Kenneth Rogoff, 1995, The law of one price over 700 years, National Bureau of Economic Research working paper no. 5132.

Kakkar, Vikas and Masao Ogaki, 1994, Real exchange rates and nontradables, Rochester Center for Economic Research working paper no. 379.

Knetter, Michael M., 1994, Why are retail prices in Japan so high?: Evidence from German export prices, National Bureau of Economic Research working paper no. 4894.

Mussa, Michael (1986), Nominal exchange rate regimes and the behavior of real exchange rates: Evidence and implications, in $\mathbf{K}$. Brunner and A. Meltzer, eds., Carnegie-

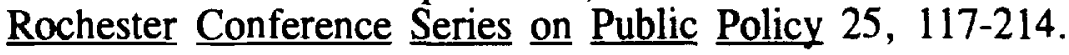


Obstfeld, Maurice and Kenneth Rogoff, 1995, Foundations of International Macroeconomics.

Razin, Assaf, 1995, The dynamic optimizing approach to the current account: Theory and evidence, in Peter B. Kenen, ed., Understanding Interdependence: The Macroeconomics of the Open Economy (Princeton).

Rogers, John H. and Michael Jenkins, 1995, Haircuts or hysteresis? Sources of movements in real exchange rates, Journal of International Economics 38, 339-360.

Rogoff, Kenneth A., 1995, What remains of purchasing power parity?, Princeton University manuscript.

Samuelson, Paul A., 1995, Facets of Balassa-Samuelson thirty years later, Review of International Economics 2, 201-226.

Stockman, Alan C. and Linda L. Tesar, 1995, Tastes and technology in a two-country model of the business cycle: Explaining international comovements, American Economic Review 85, 168-185.

Wei, Shang-Jin and David Parsley, 1995, Purchasing power disparity during the floating rate period: Exchange rate volatility, trade barriers and other culprits, Harvard University, Kennedy School of Government, working paper. 
Figure ।

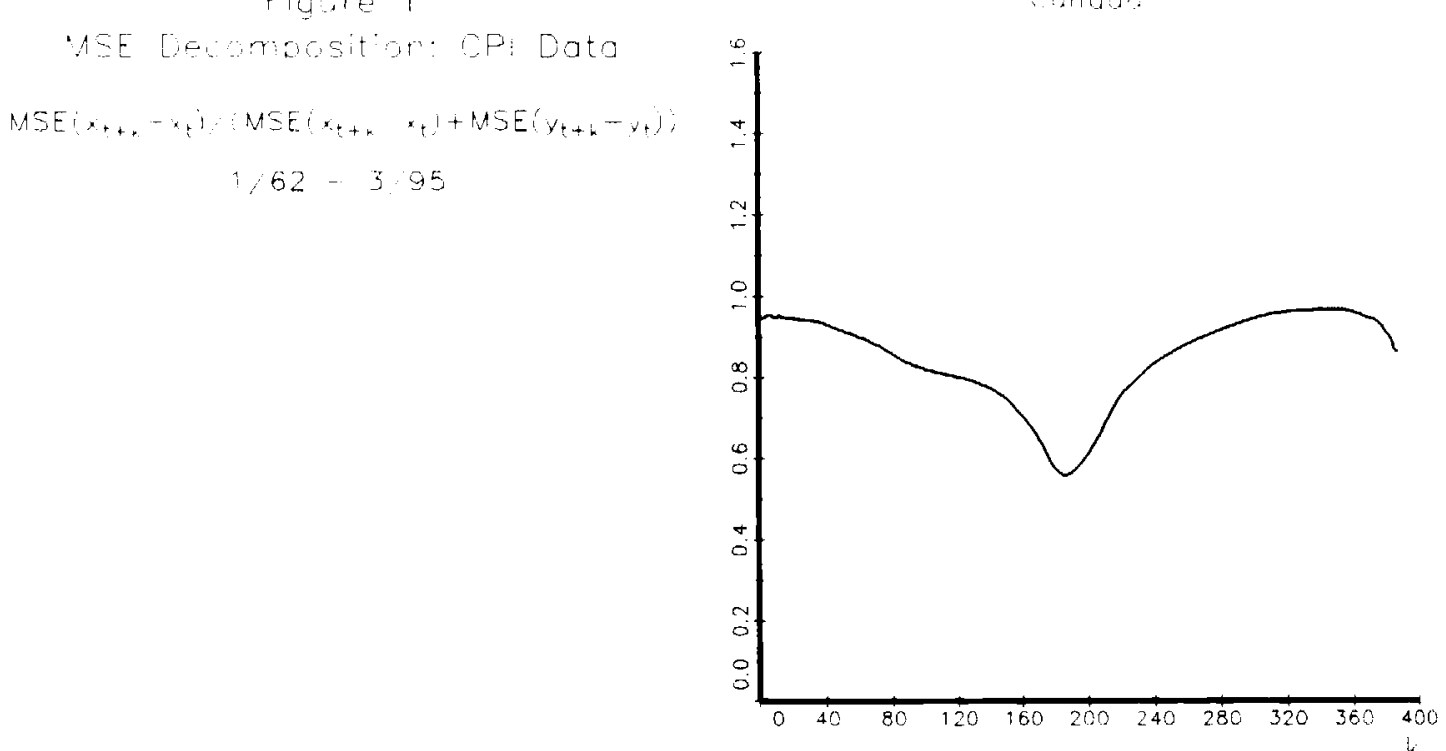

German.

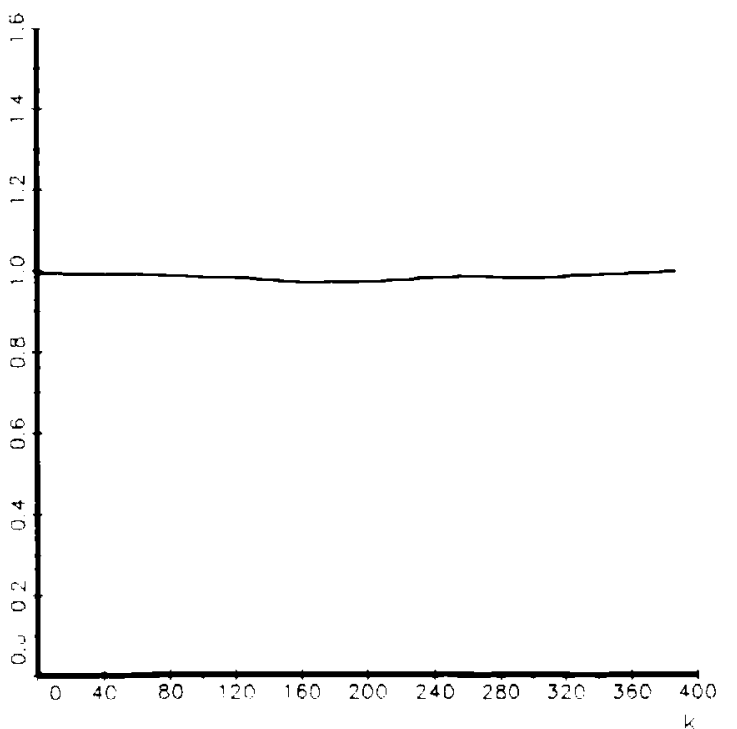

Ito l:

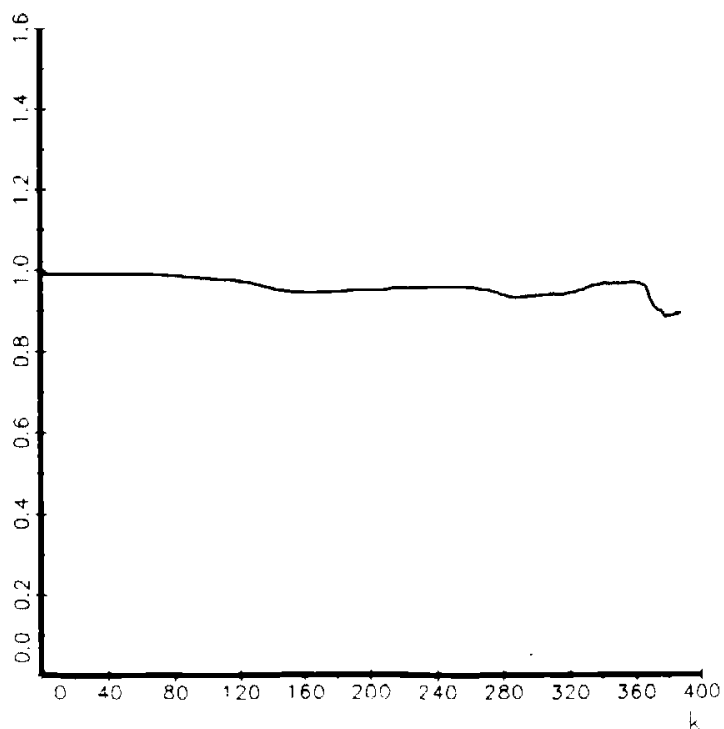

France

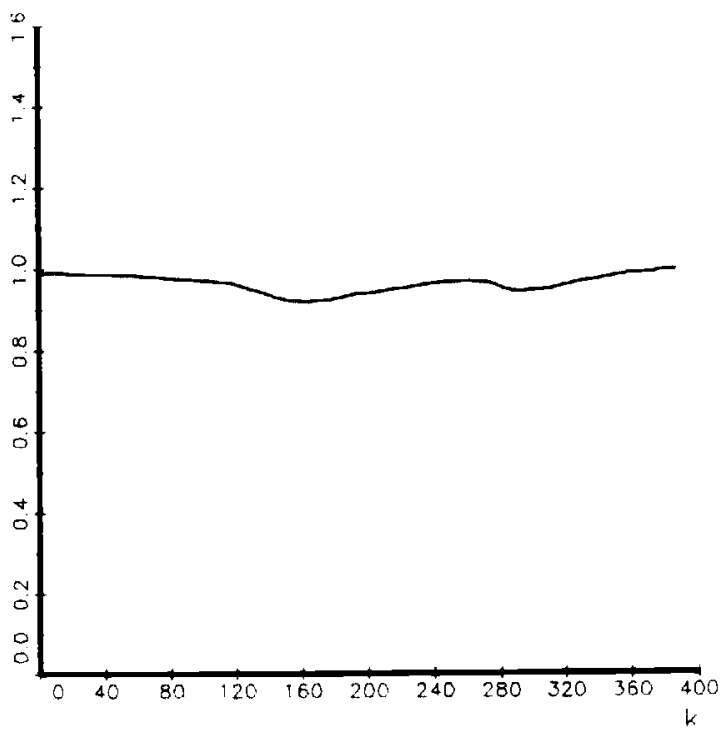

Japan




F. glite 2

arionce Decompstior: CPI Data

$\left.\left.\operatorname{var}\left(x_{t+k}-x_{t}\right) \operatorname{var} x_{t+k}-x_{t}\right)+\operatorname{var}\left(y_{t+k}-y_{t}\right)\right)$

$162-3 / 95$

Germany



anada

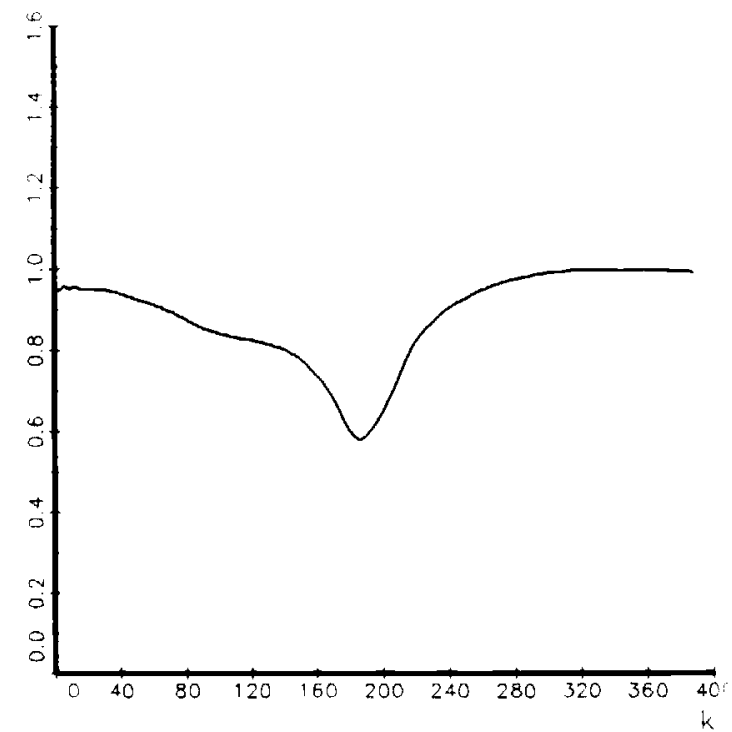

Italy

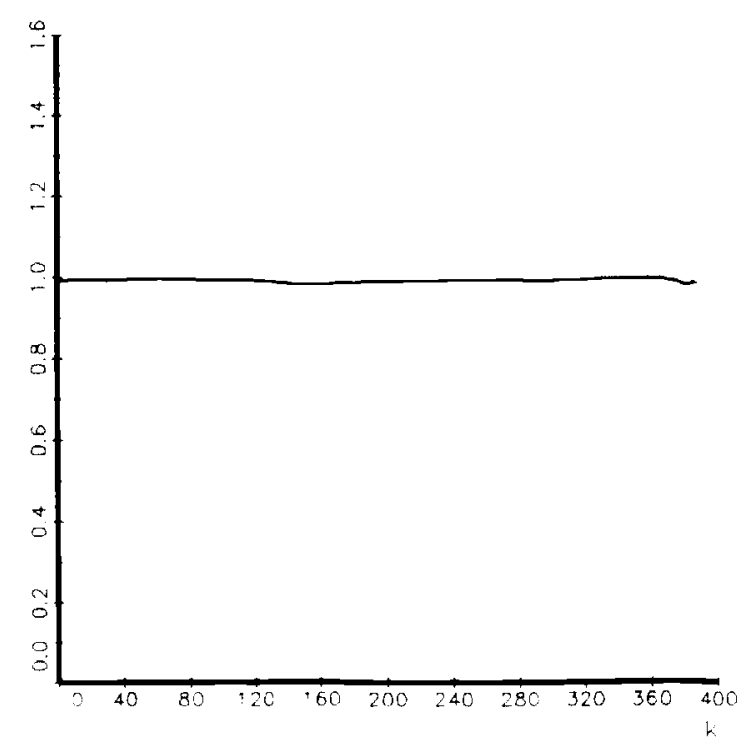

Fronce



Japan

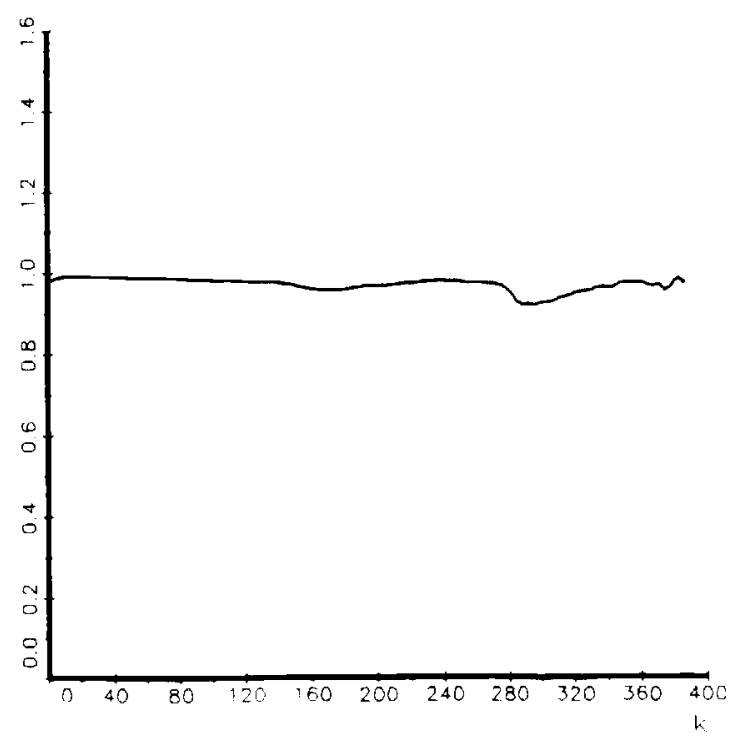


Figure 3

Drift Decomposition: CPI Dato

$$
\operatorname{Drift}(x) /(\operatorname{Dr} f t(x)+\operatorname{Drift}(y))
$$

$1 / 62-3 / 95$
Sanodo

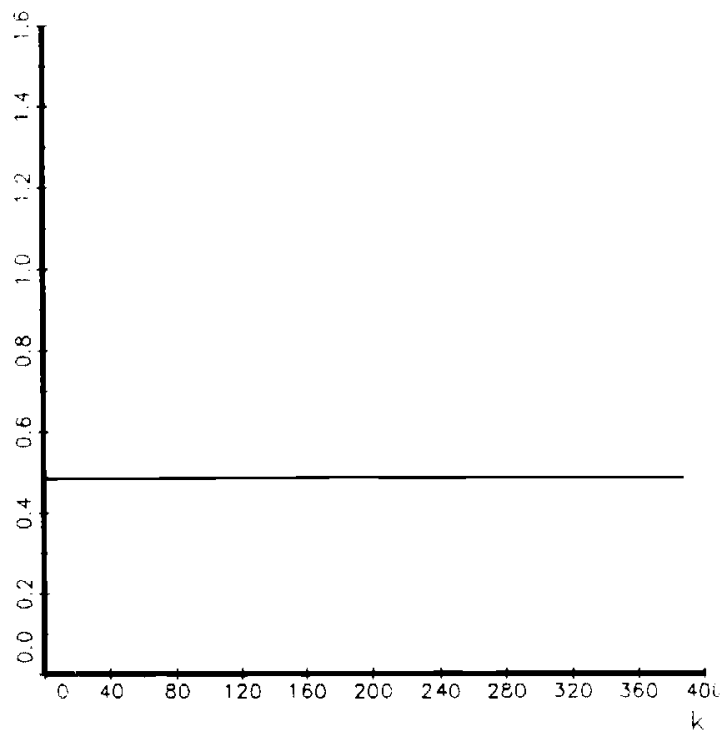

Italy



France

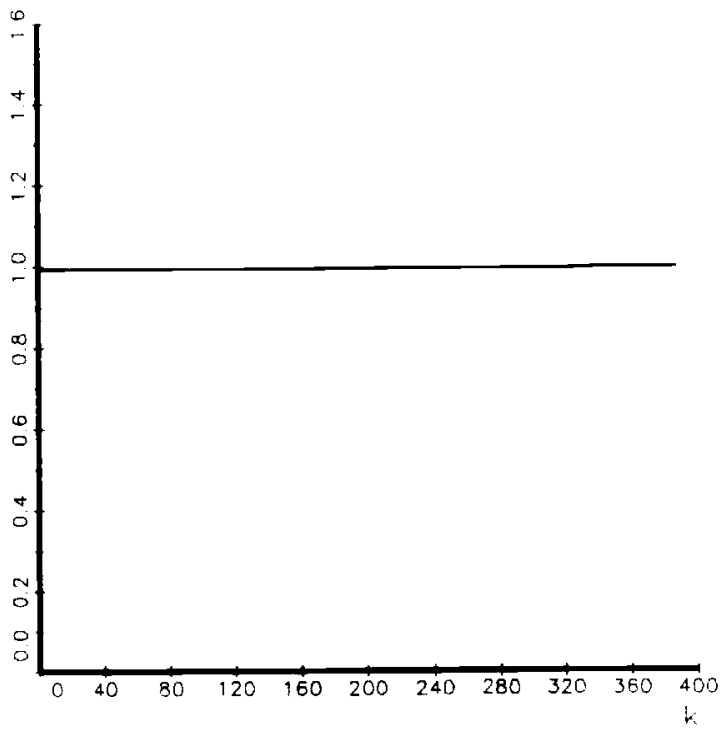

Japan

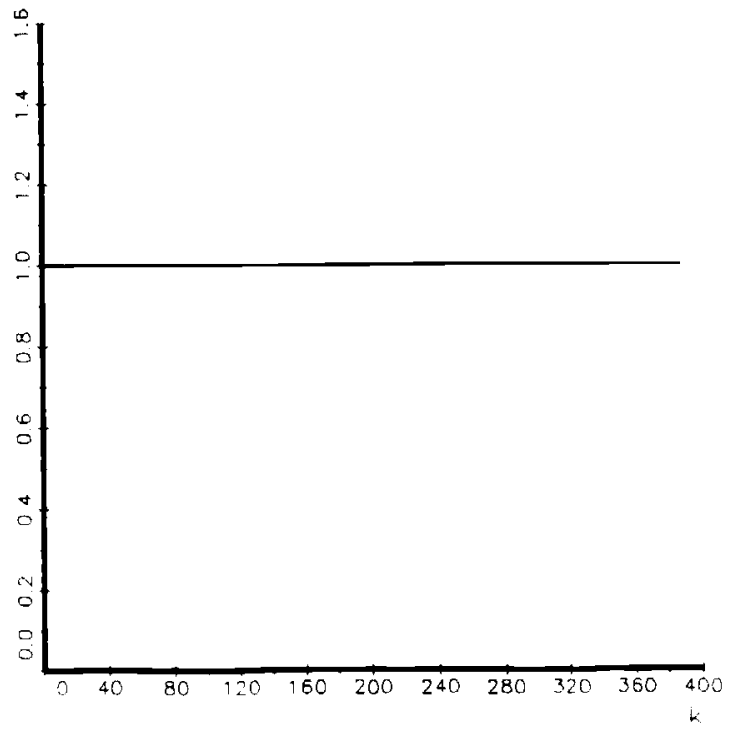


Figure 4

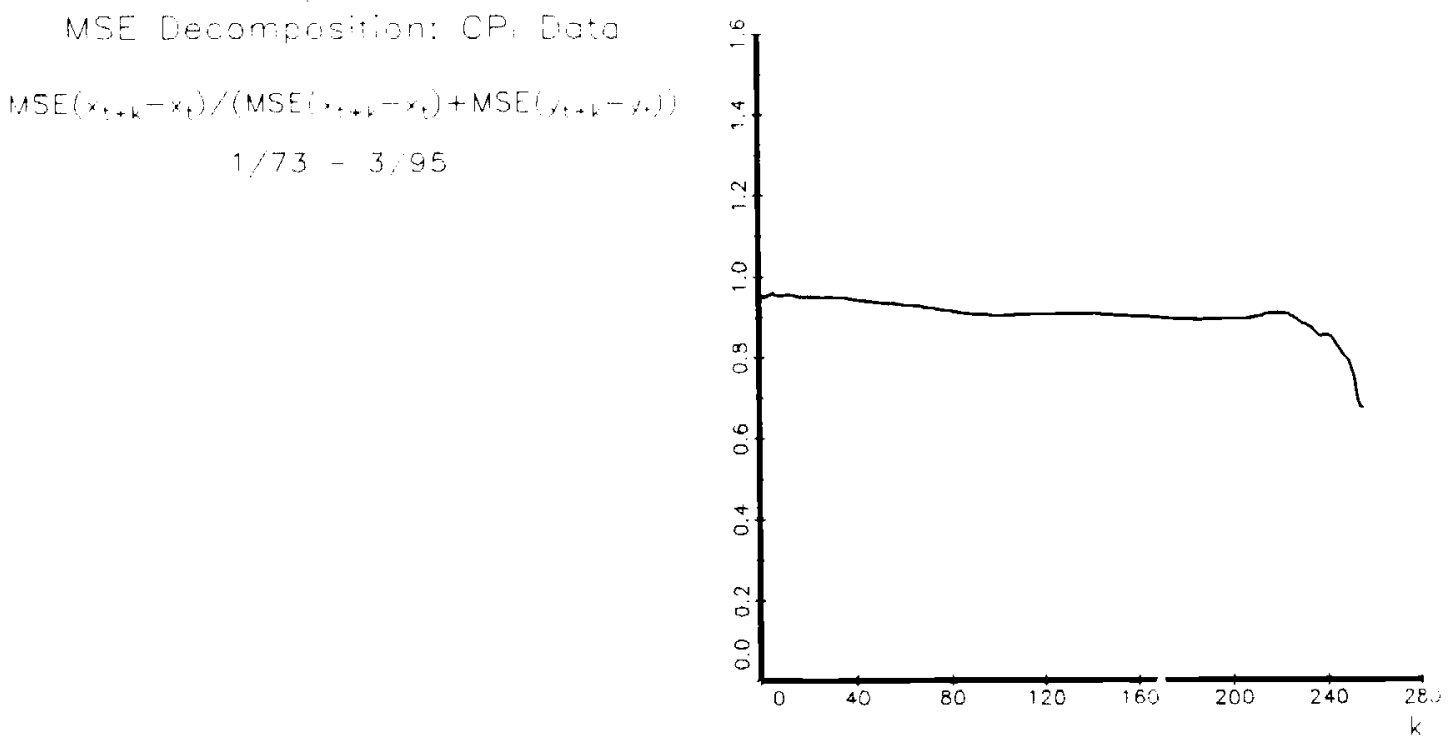

Germany

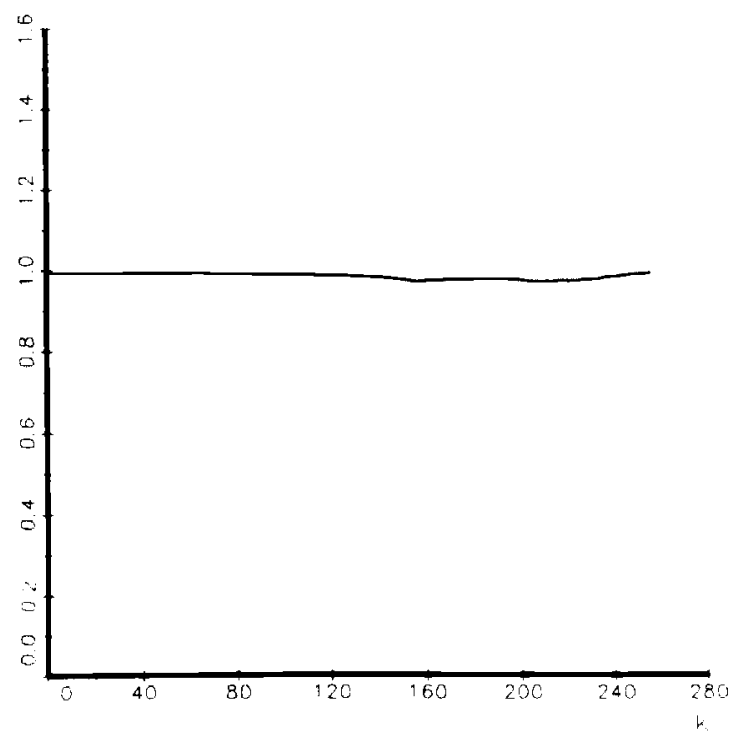

$6 \cdot 91:$

France

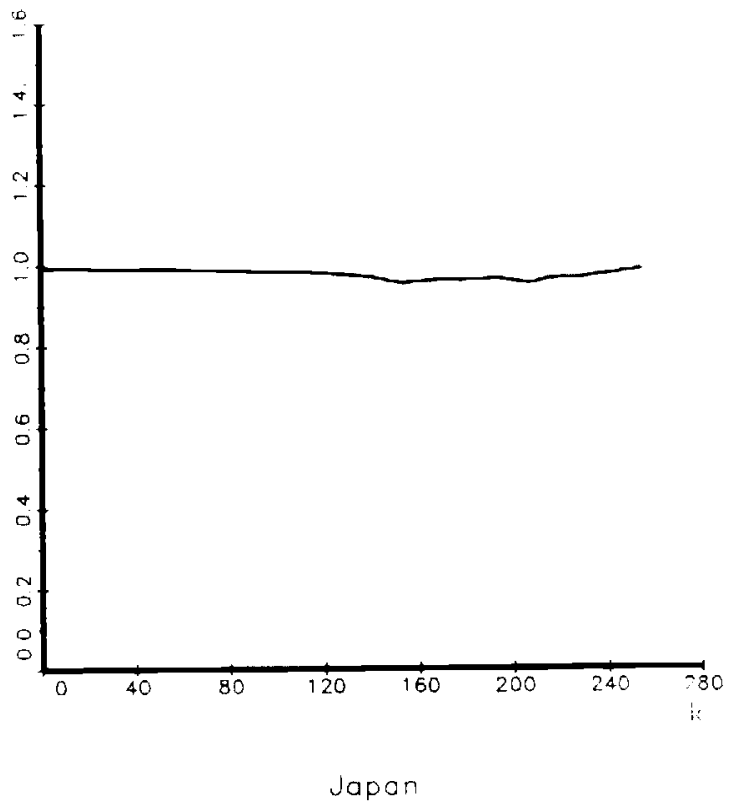

it an
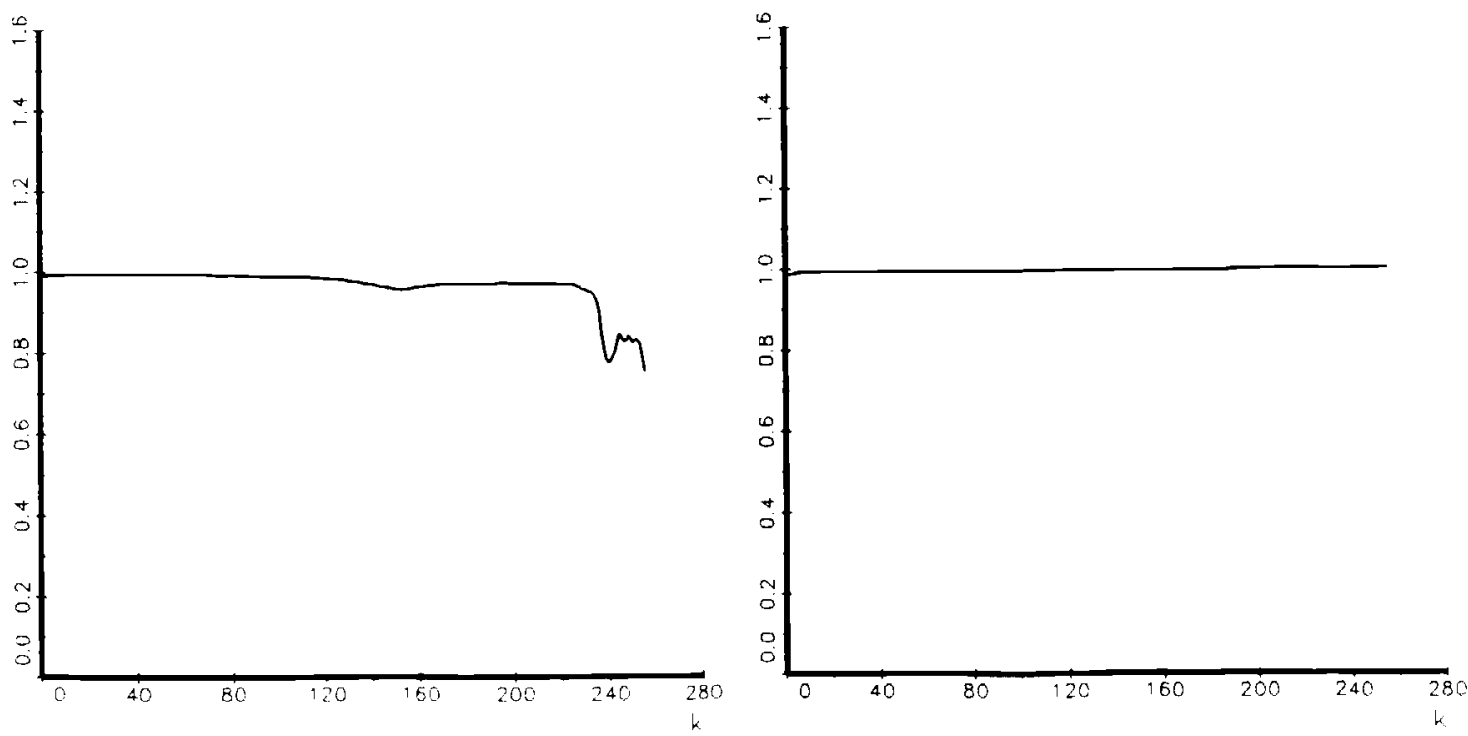

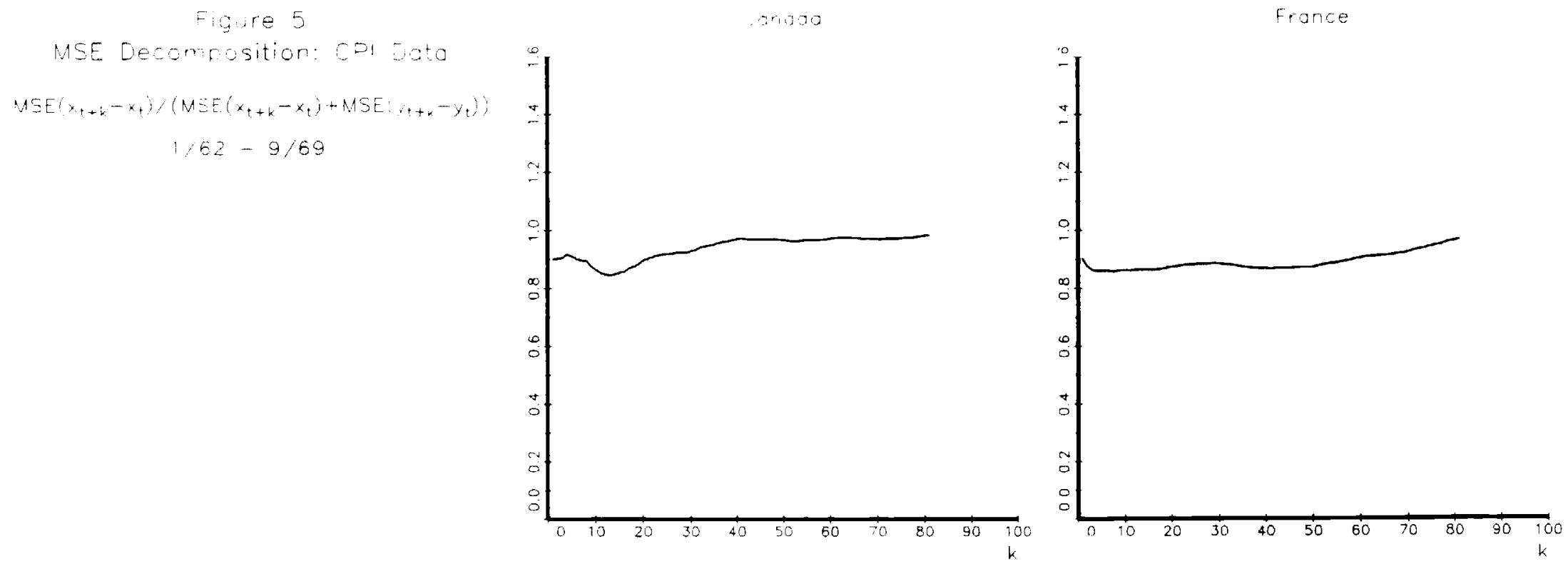

Germany

italy

Japan
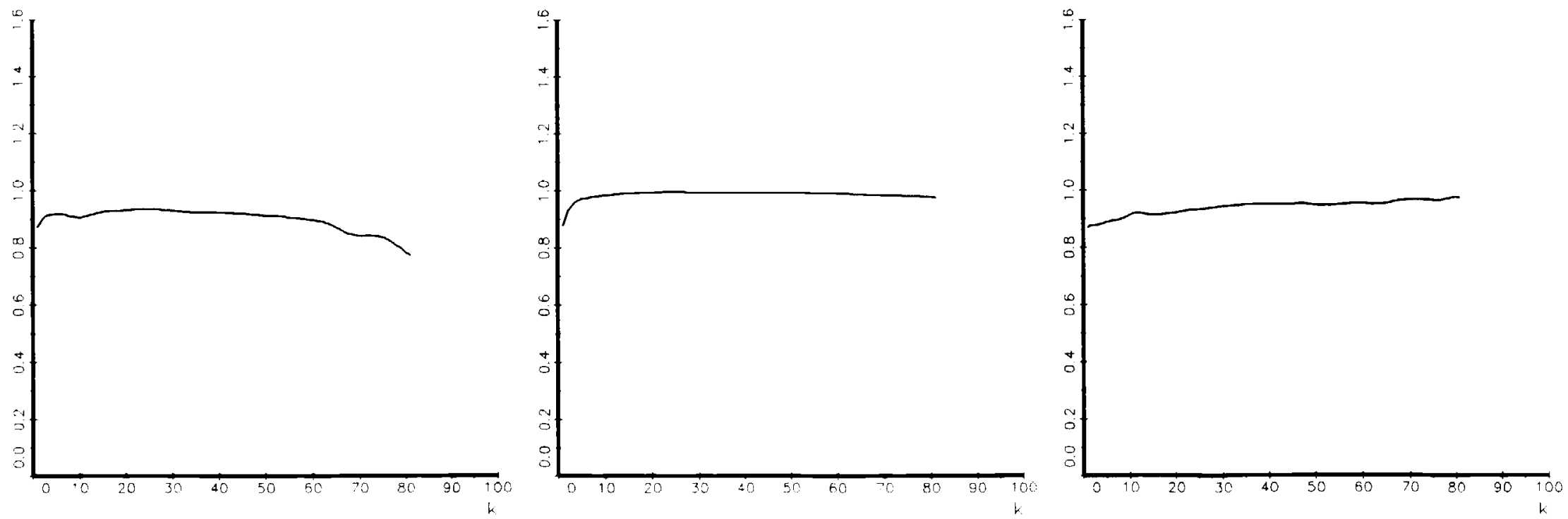


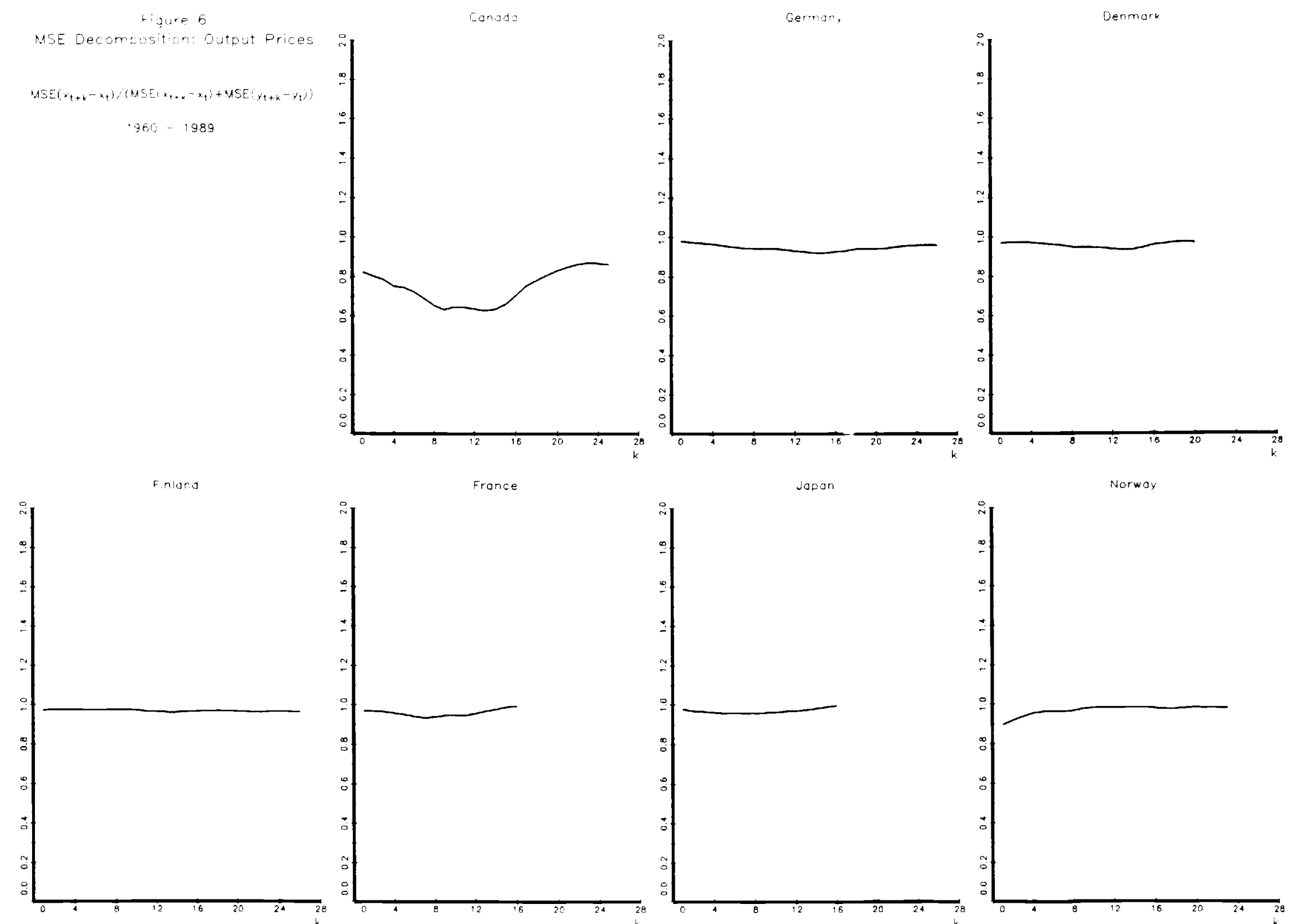


<smiles>C1=C[SiH][SiH]=C1</smiles> 
Figure 8

MEE Oecomposition German Real Exchange Rates

c.1.3/79-6/93

Output Frices 1979 - 1990
France relative to Cermany

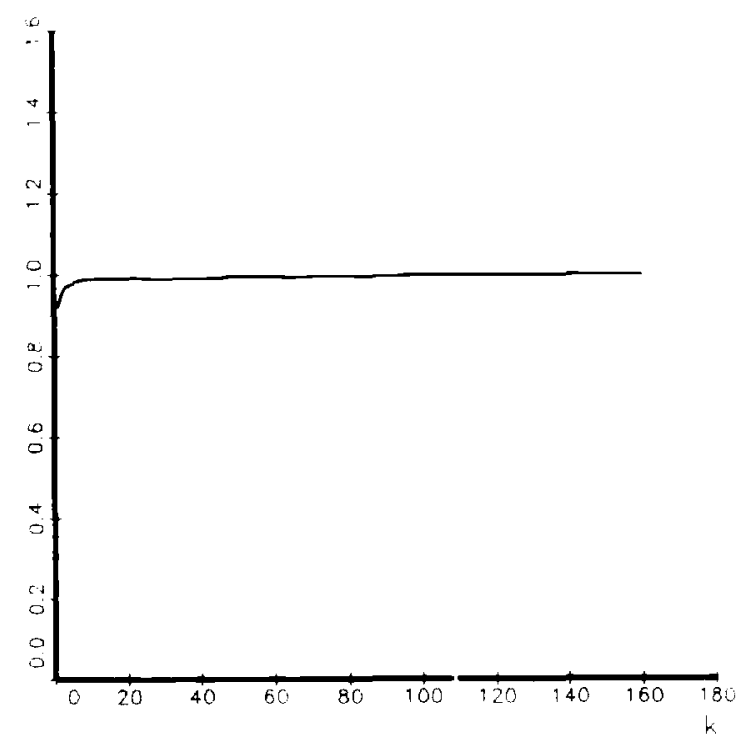

France relative to Germany

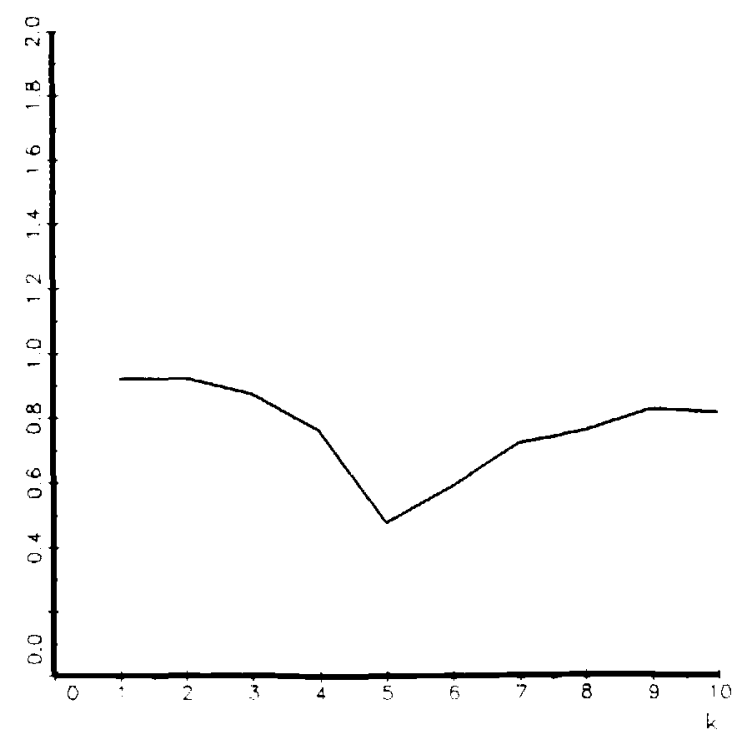

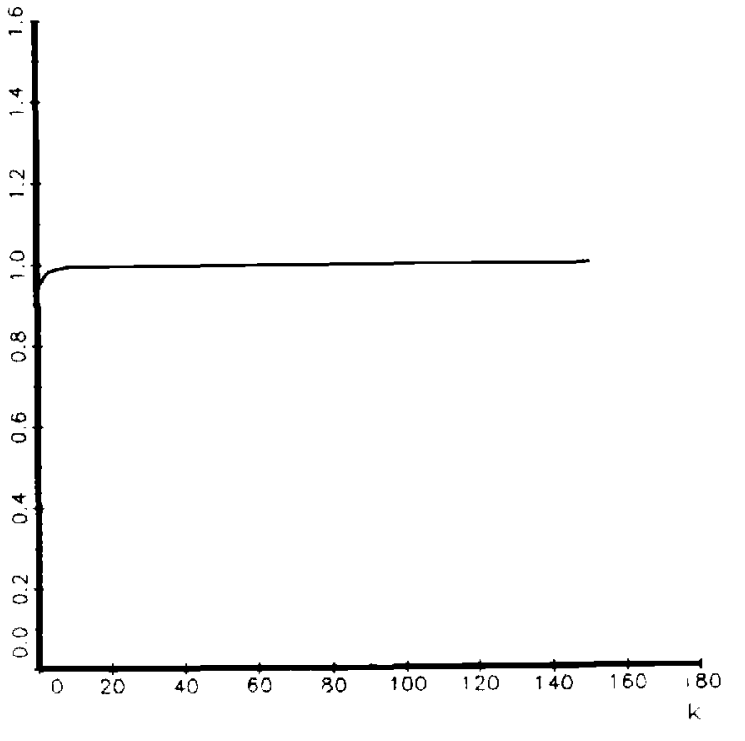


figure 9

MSE JEc -rmastion: Fersono Consumet: Expenditure Prices

$\left.\operatorname{MSE}\left(x_{1+n}-\cdots\right) \quad M E E x_{t+n}-x_{t}\right)+\operatorname{MSE}\left(y_{t+n}-y_{t}\right)$ $19+1-1994: 4$
Eanoda

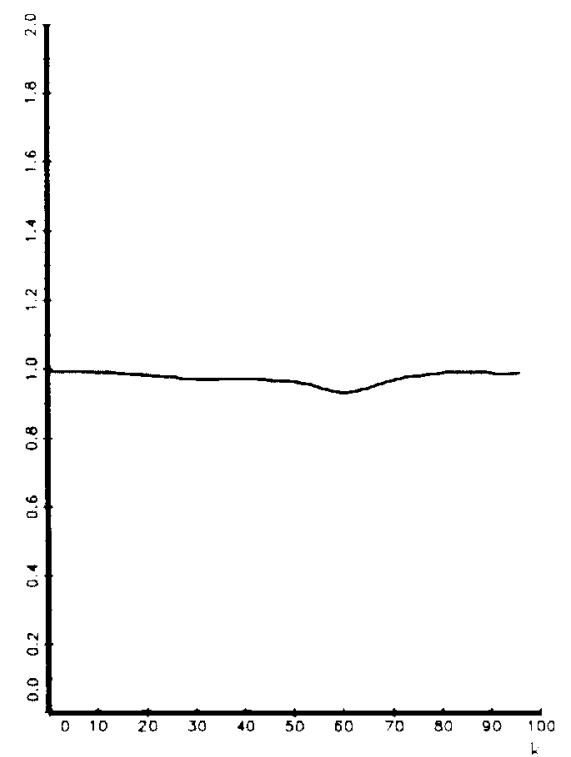

Japon

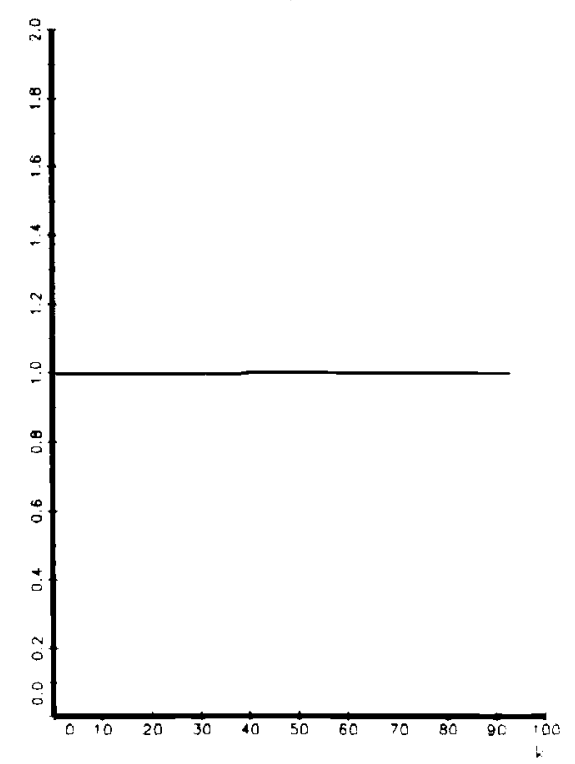

France

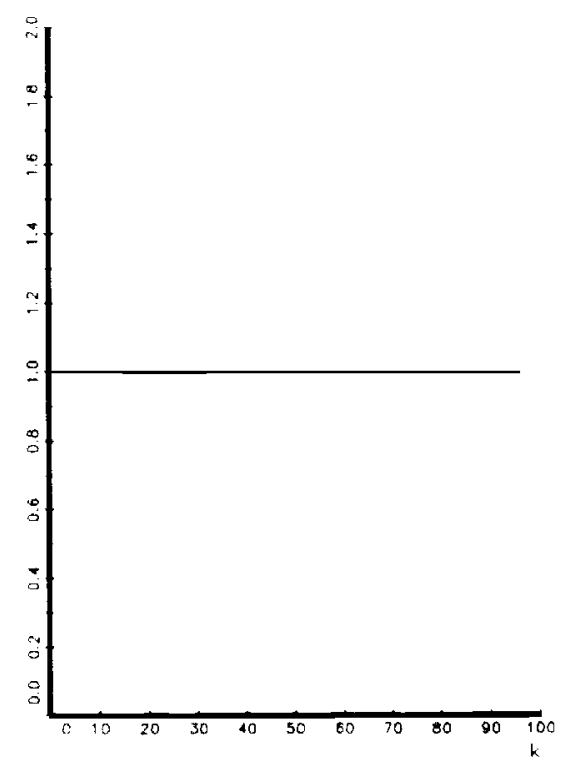

Sweden

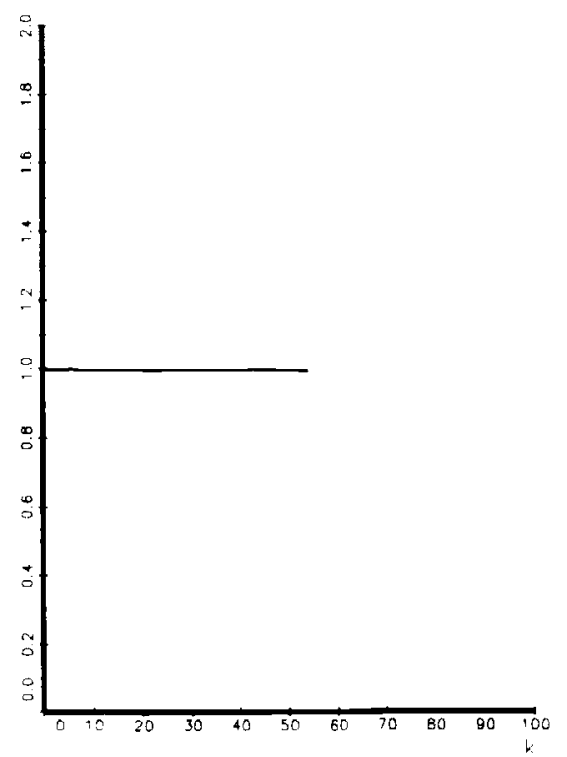

toly:

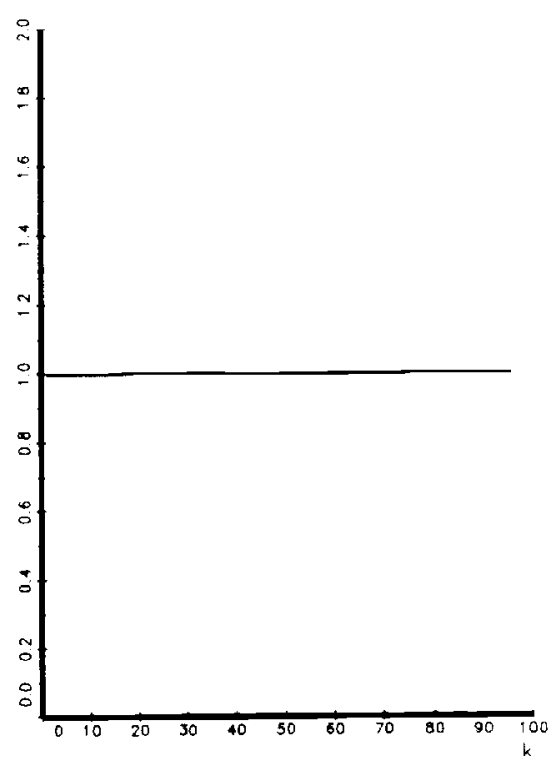

United kingdom

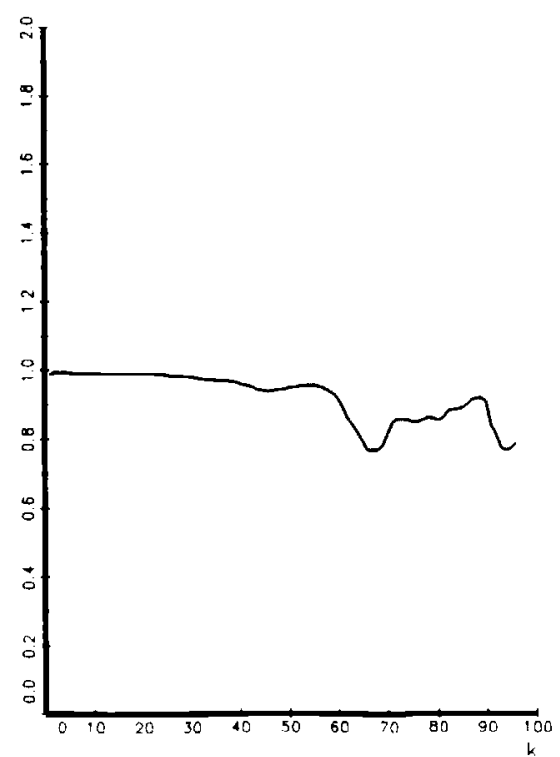


Figure 10

MSE Decombosition CP and PPI Dato

PPI = Prce of Traded Goods

CFI = Price of All boods

$1 / 72-5 / 95$

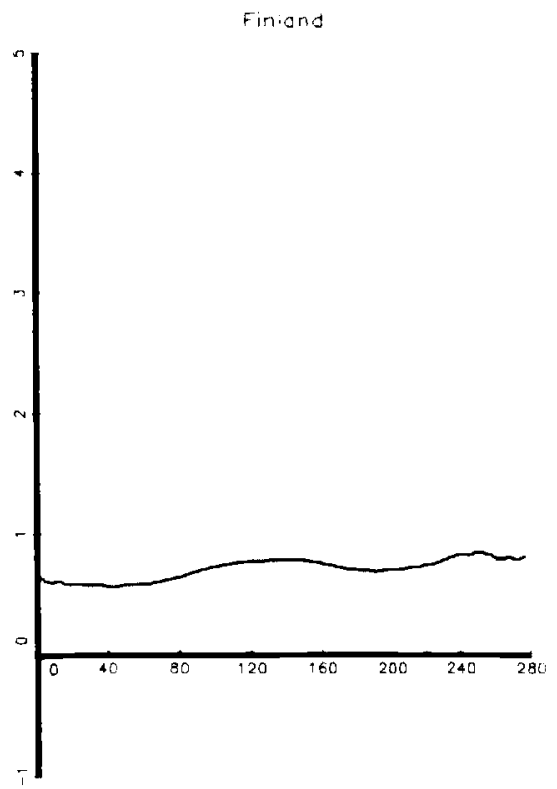

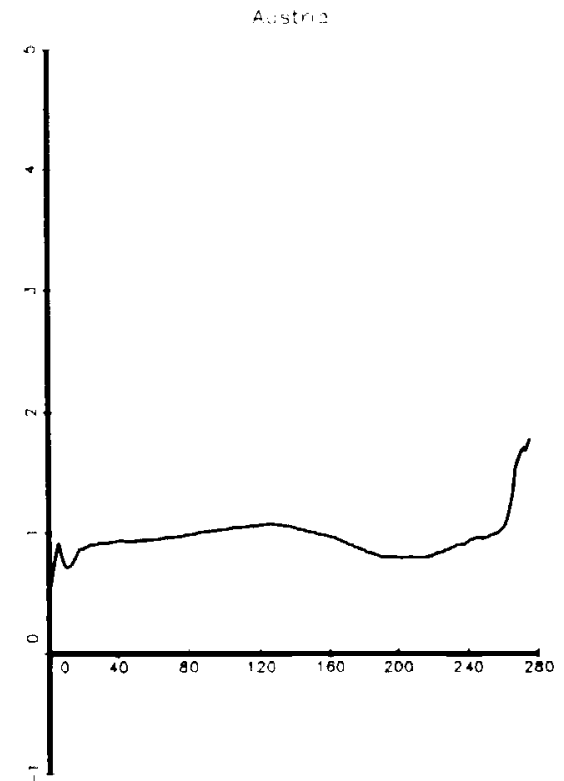

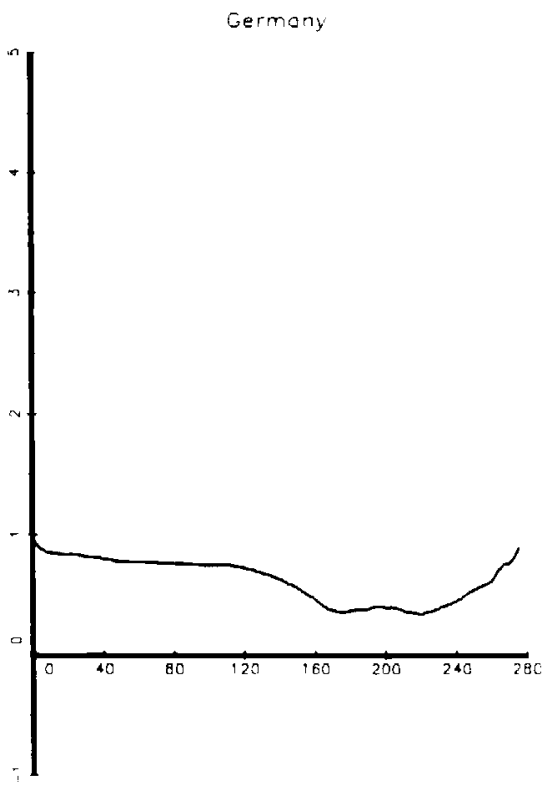

Greece
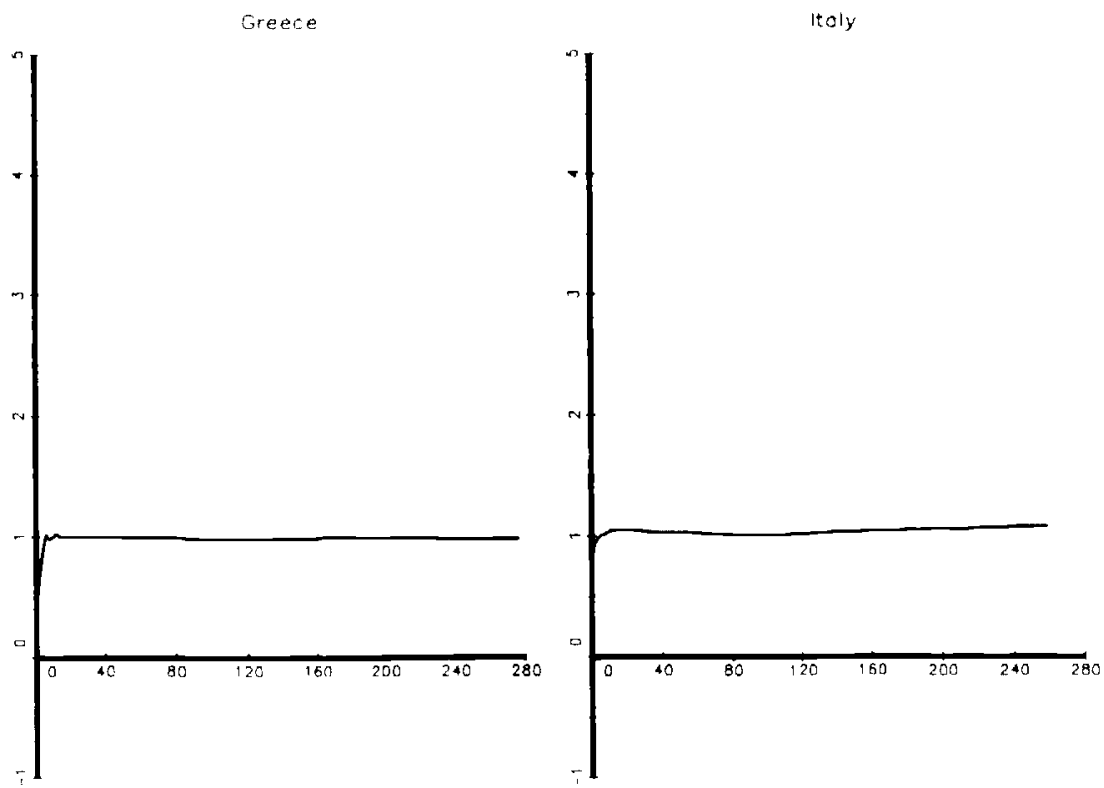
Figue 10

(p. 2)

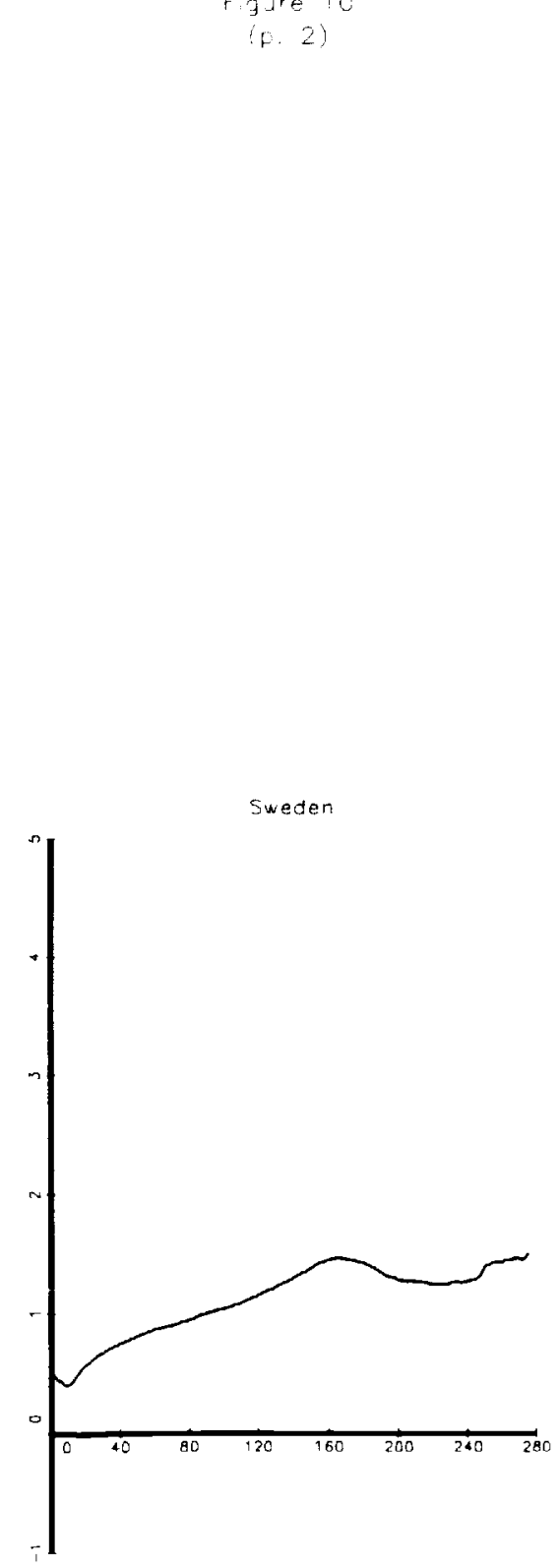

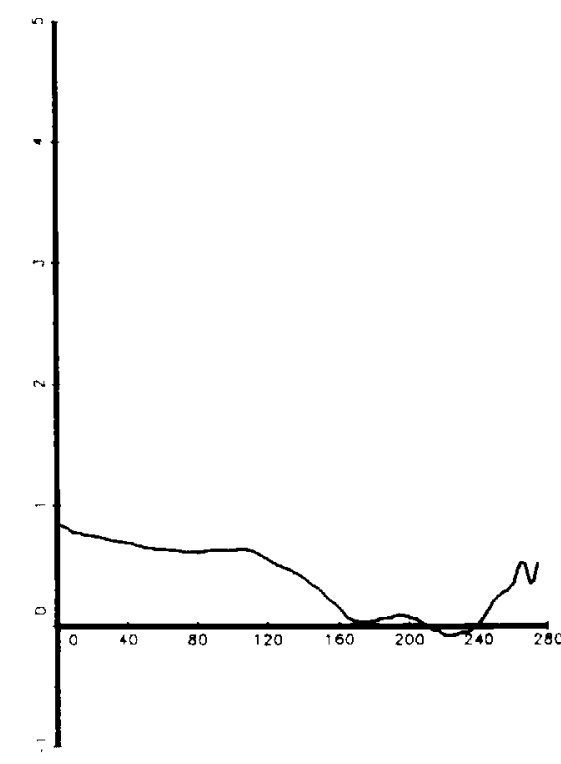

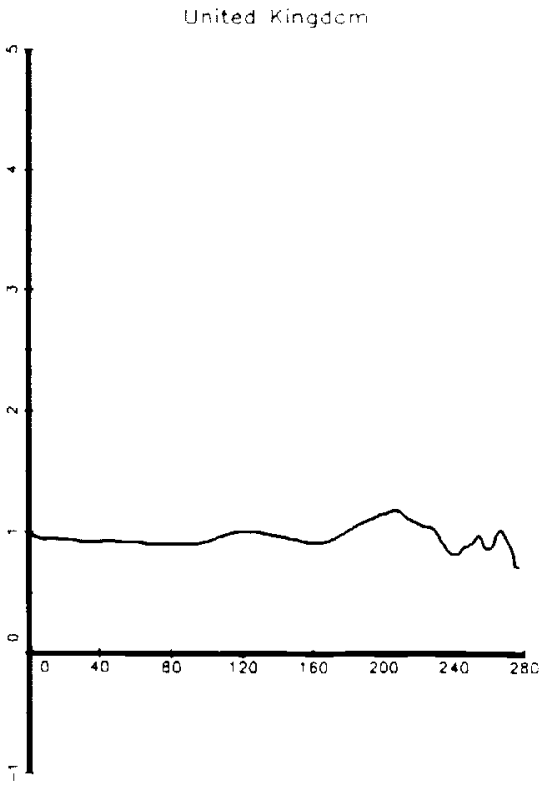

Denmork.

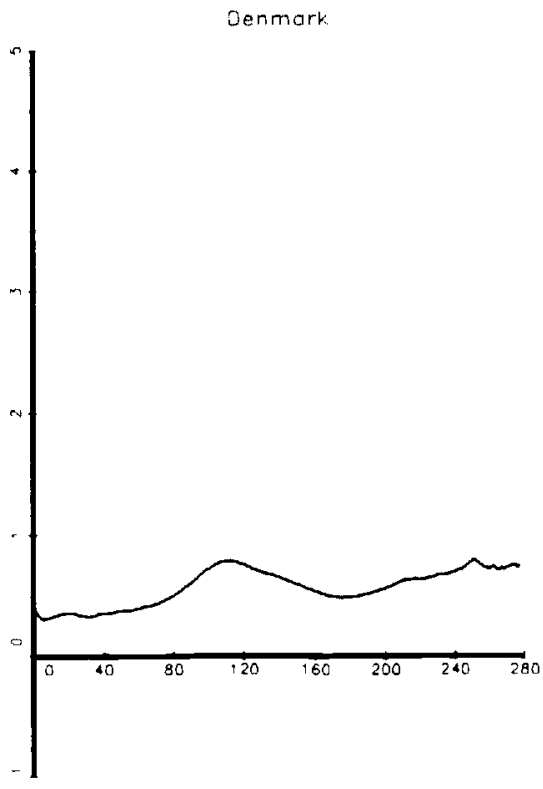

Spoit

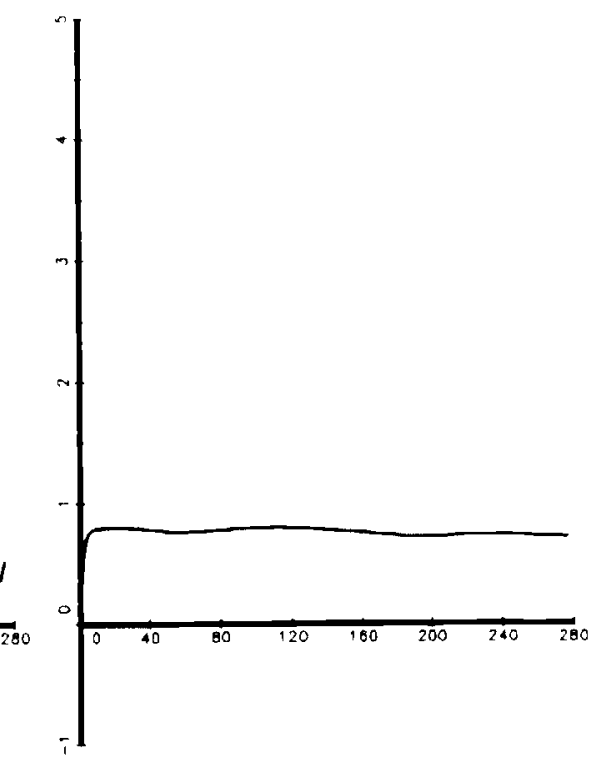

Norway




Figure 0

(f) 3

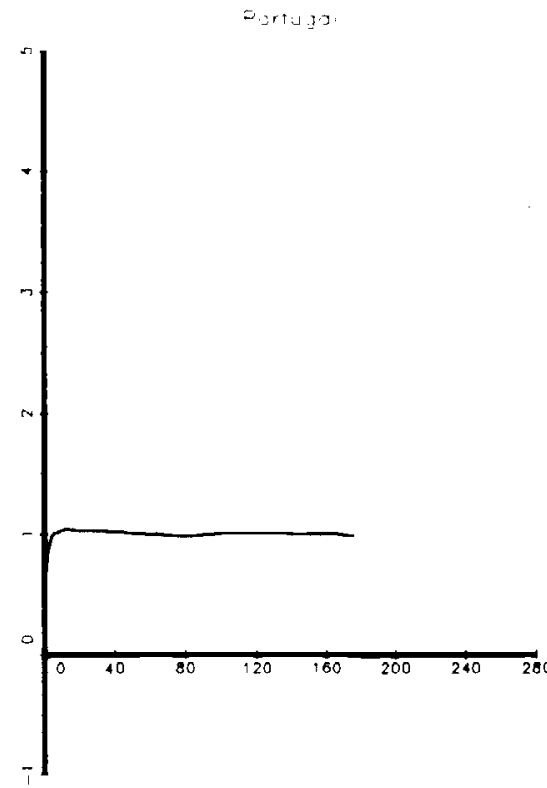

Canoso

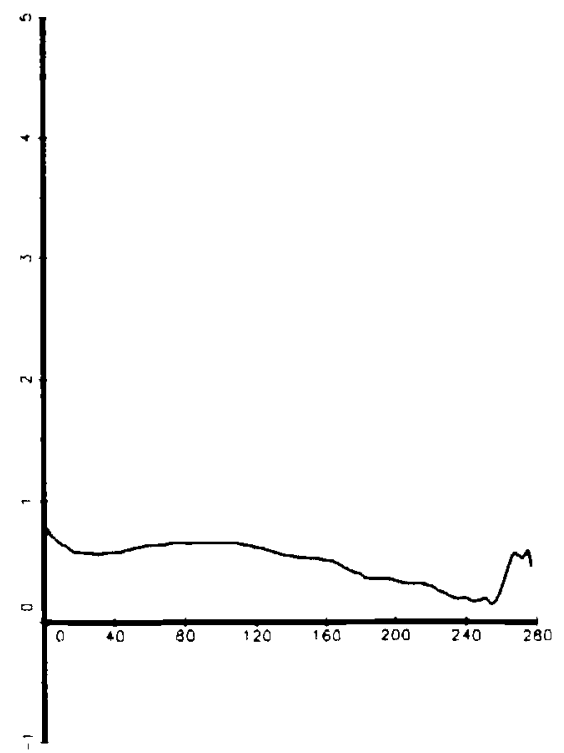

Switzeriand

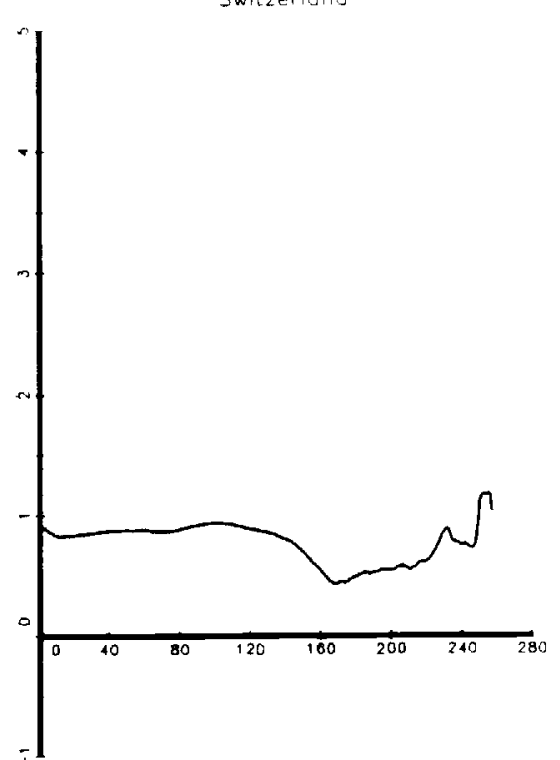

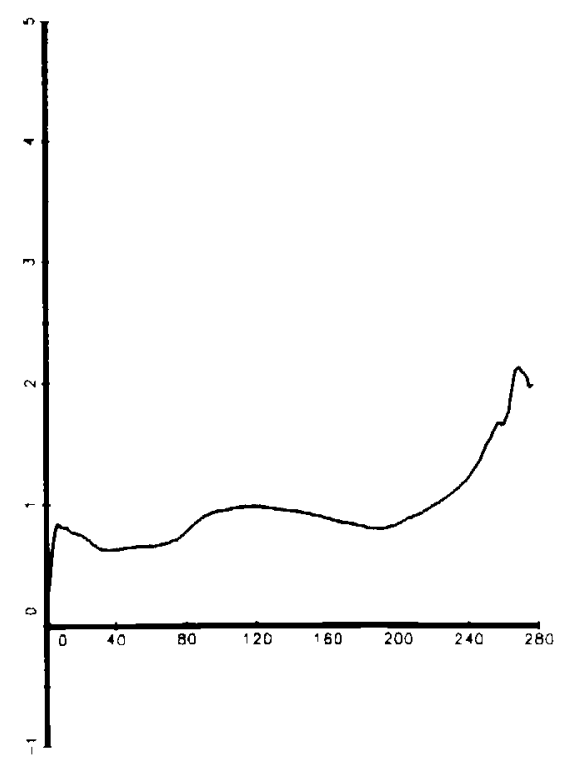


Figure 11

The U.S. / Japan Real Exchange Rate CPI-based and PPI-based Measures

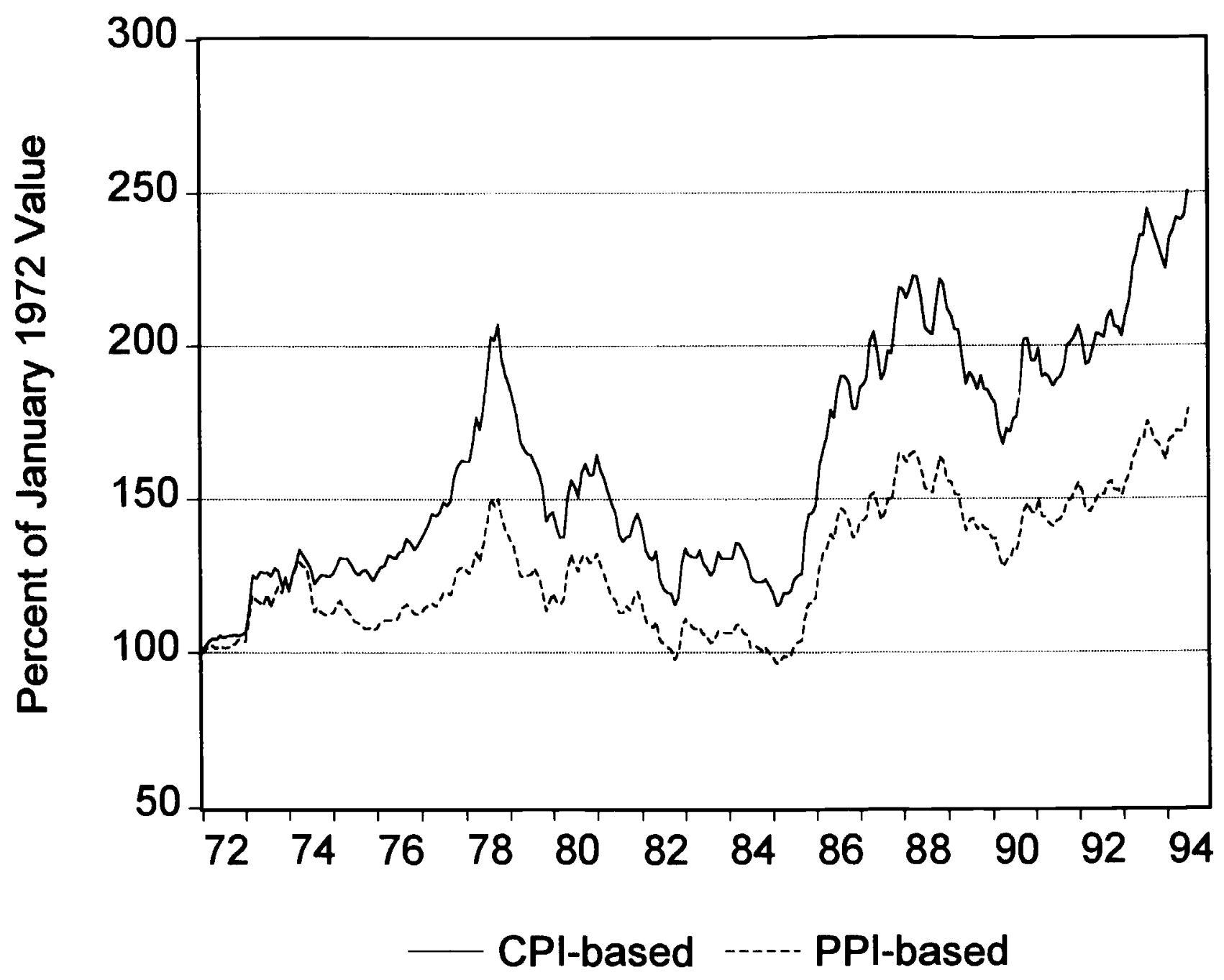




Figure 13

Price of Japanese Corporate Services

Relative to the Overall Japanese CPI

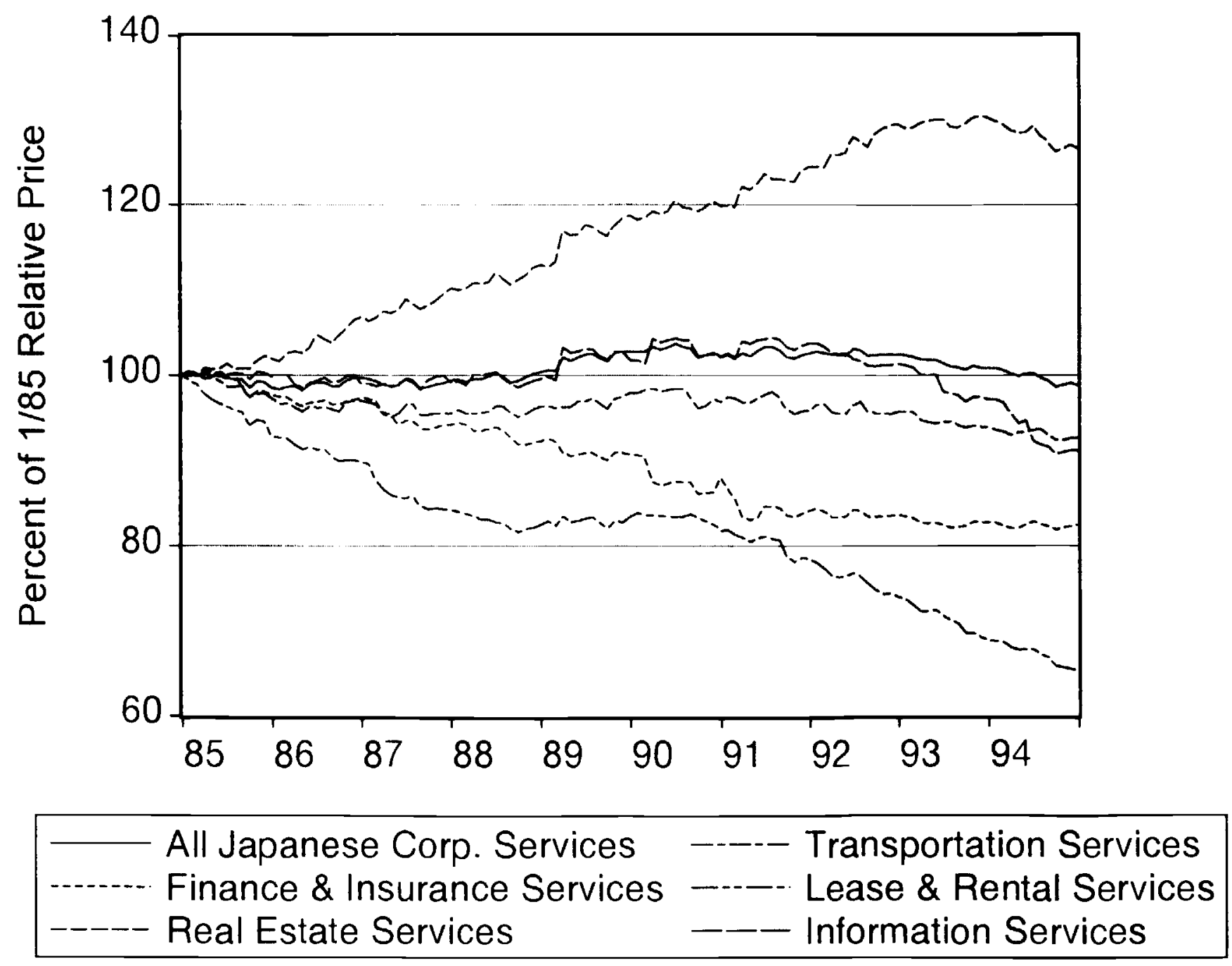


<smiles>CC1C2CC3C(C)C1(C)C23C</smiles> 
Figure 15

MSE Decomposition: Meosurement

Error in Traded Goods Prices

$y=2 / 3$
$3 / 79-6 / 93$



|taly

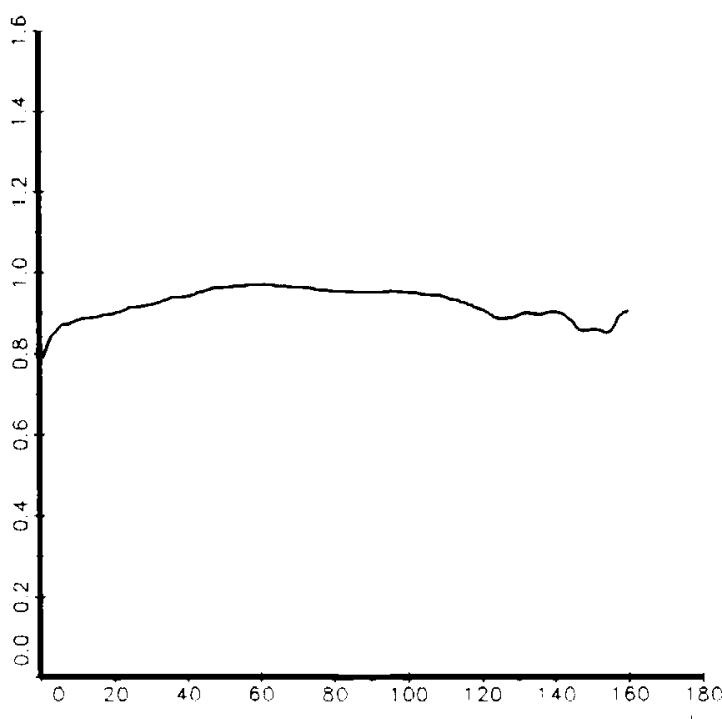

France

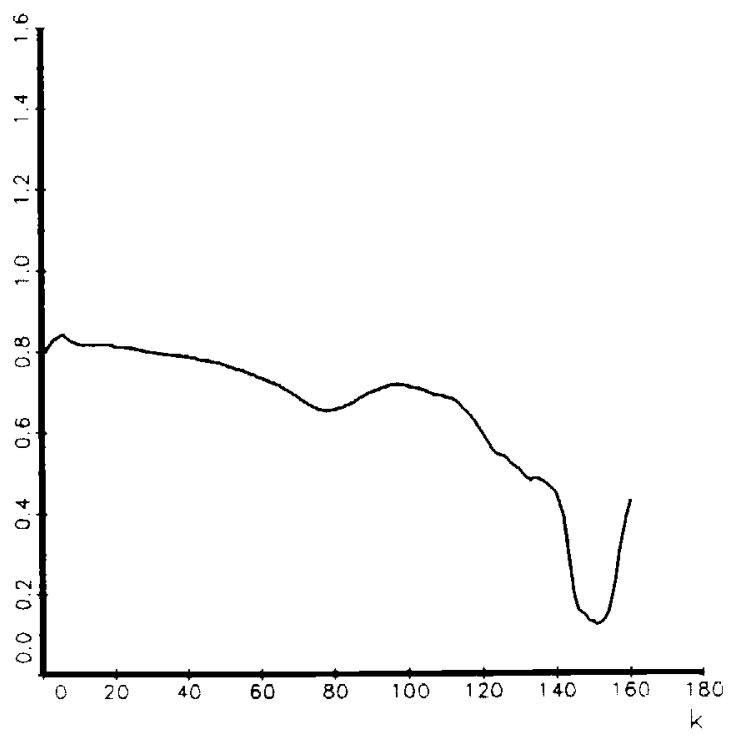

Japan

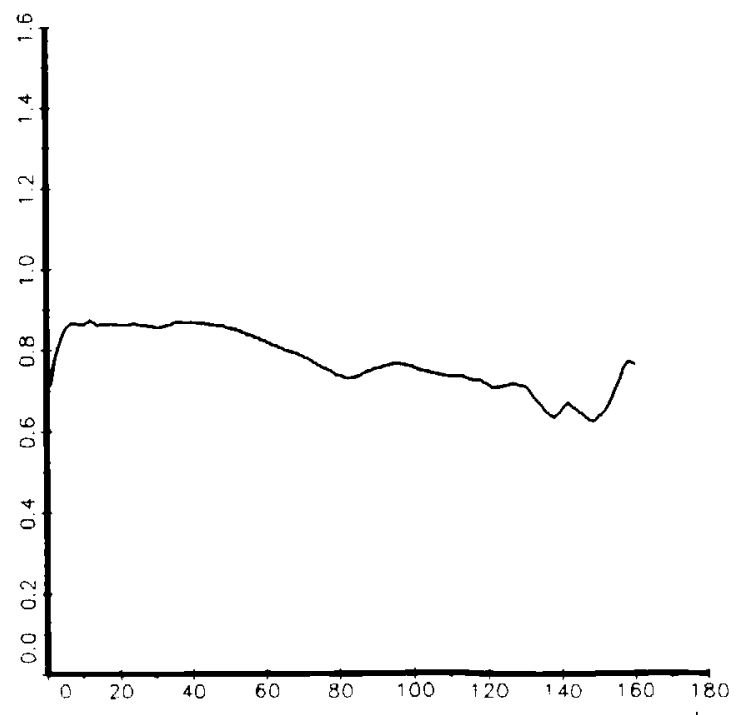


Figure 16

MSE fffect of variation in the Terms-of-Trode CF: Orices $1,62-3 / 95$

Germany

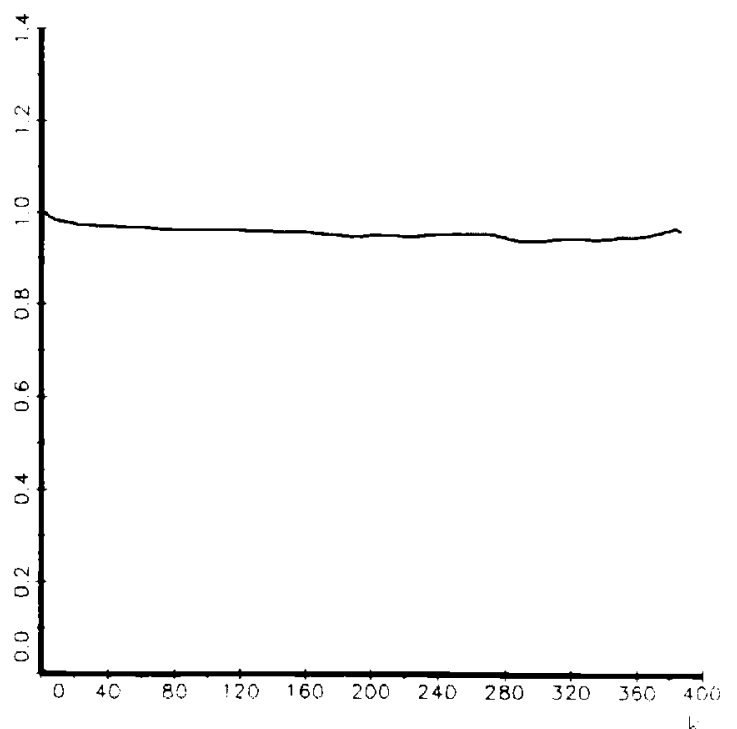

Sondo



1taty:

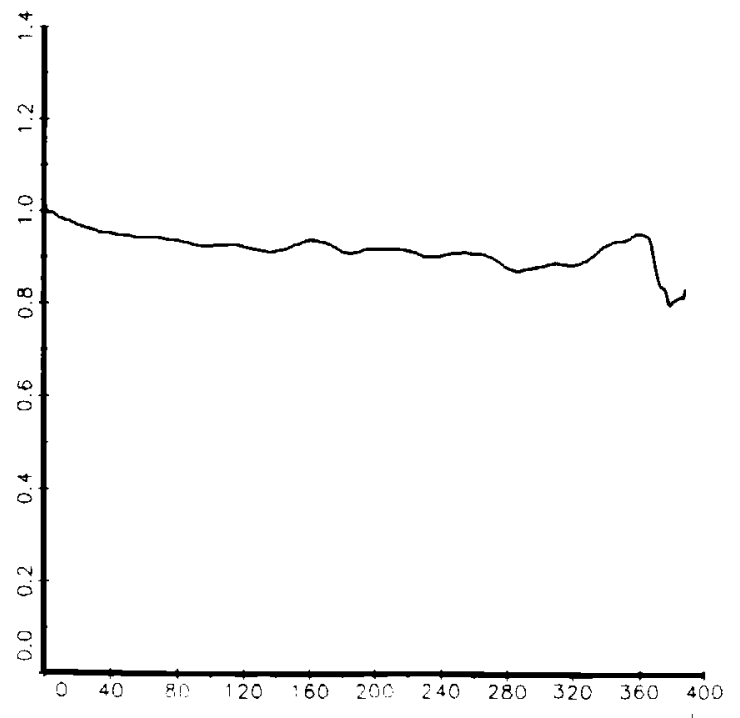

France




France

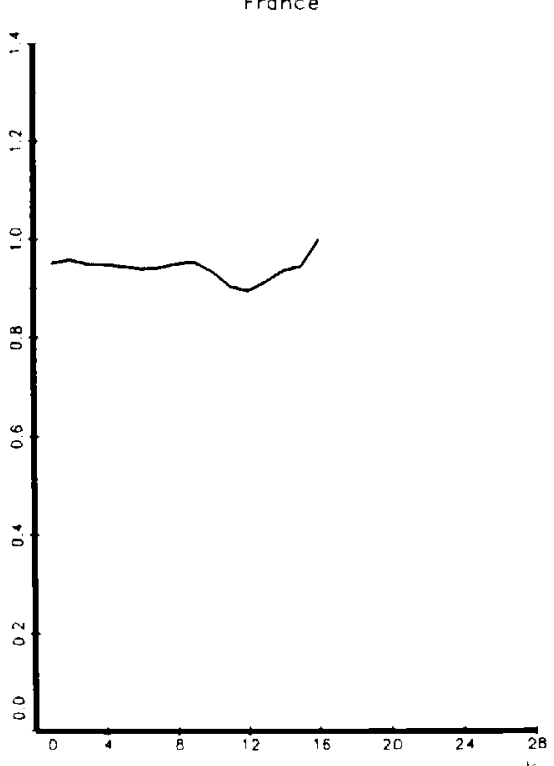

Germany
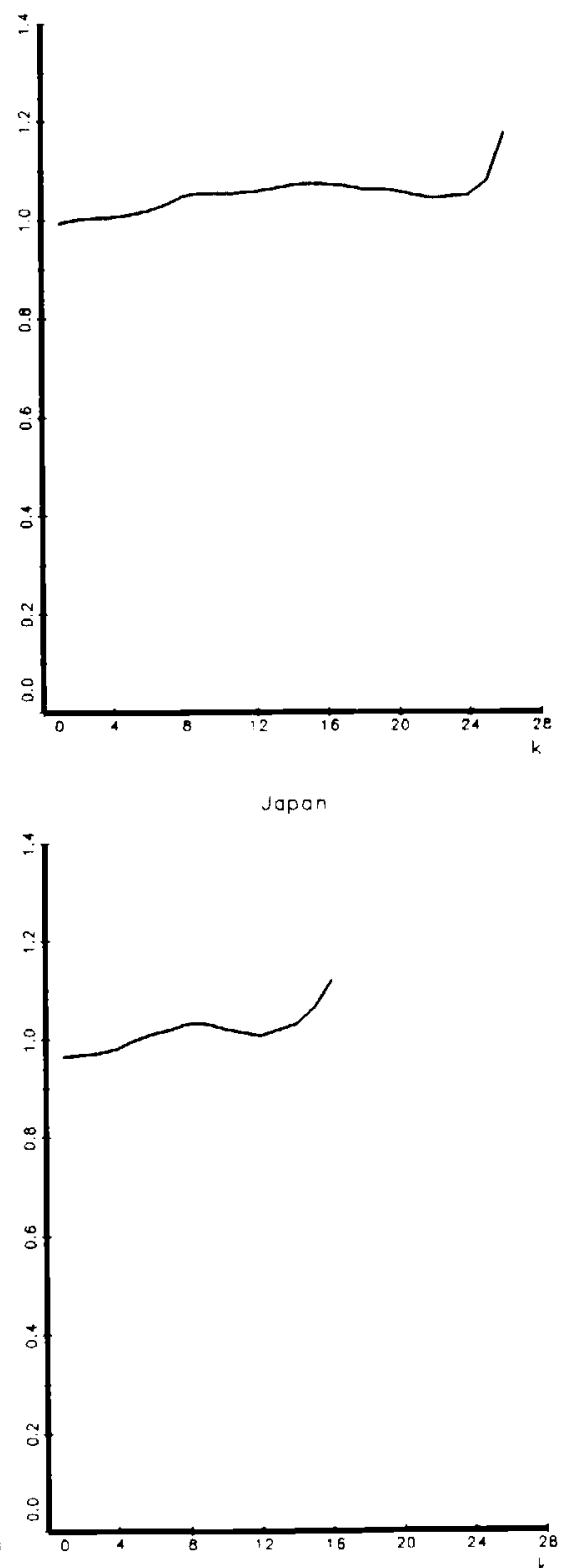

Denmark
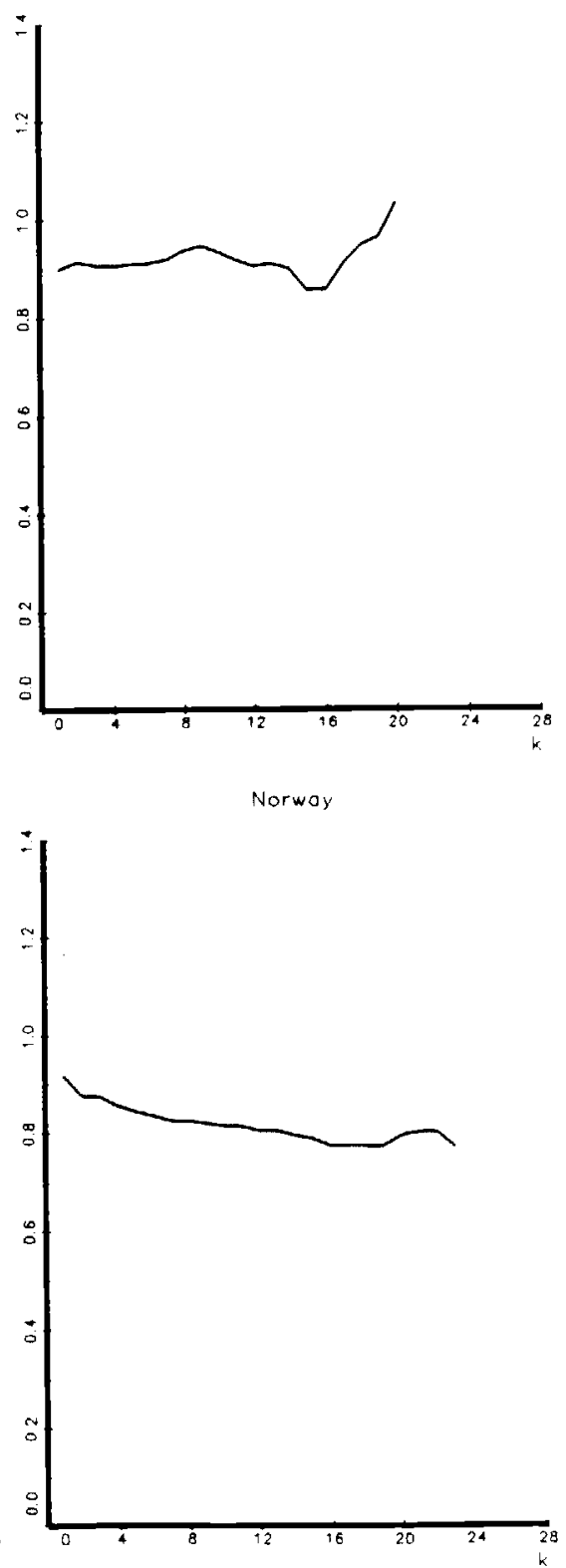